Brocar, 18 (1994) 49-86

\title{
VEINTE AÑOS DE HISTORIA MODERNA EN LA RIOJA
}

\author{
José Luis Gómez Urdáñez*
}

\begin{abstract}
RESUMEN: El artículo trata de analizar el desarrollo de la historiografía sobre la época moderna en La Rioja en los últimos veinte años. Se describen los objetivos perseguidos en cada etapa por los investigadores, matizando la diferencia entre los que trabajan en torno al mundo universitario y los que se mantenían anclados en la tradición del eruditismo local. El contraste científico que los primeros obtenían en el mundo académico favoreció el desarrollo de una histioriografía renovadora y progresista, que supone una plataforma que la creación de la Universidad de La Rioja impulsa.
\end{abstract}

ABSTRACT: In this paper the reader will find about the developement of histiographical research in La Rioja in the latest 20 years, in the field of Modern Age studies. The reader will also find a number of critical approches comings from university research as well as from the work by local scholars sponsored by the Rioja Studies Institute. This woork is today part of research carried out in the University of La Rioja.

\section{AÑOS DE PENITENCIA}

Hace veinte años veía la luz el primer número de Cuadernos de Investigación (Geografía e Historia), la revista que empezó a editar el Colegio Universitario, entonces de Logroño, luego, de La Rioja. A juzgar por su contenido, los mentores de la nueva revista no tenían todavía intenciones de indagar en el pasado riojano; los dos fascículos del tomo I contenían artículos de historia de Aragón ${ }^{1}$, firmados por el pro-

* Profesor del Departamento de Ciencias Humanas y Sociales, Area de Historia Moderna, de la Universidad de La Rioja.

1. Para una mejor comprensión del texto, se ha optado por modificar las normas de publicación en relación a las notas, incluyendo también el título de la obra y otros aspectos de interés. MAISO GONZÁLEZ, 1975: "La coyuntura económica de Aragón a mitad del siglo XVII y el motín contra los valones" y "Baltasar Carlos y Zaragoza". 
fesor del centro, y otros sobre temas generales, a cargo de profesores de la Universidad de Zaragoza ${ }^{2}$. Como veremos, la historia regional era todavía, genéricamente, un denostado lugar común de la historia positivista en manos de eruditos locales al servicio del ultraconservadurismo ideológico imperante en la oligarquía riojana ${ }^{3}$.

El Colegio Universitario, fruto de las desazones políticas de las dos familias del régimen, que debían exhibir algún logro cultural en la desatendida ciudad, se había fundado en 1972 con la pretensión de cobijarlo bajo la influencia de la Universidad de Navarra; sorprendentemente - con el consiguiente escándalo de la jerarquía de la ciencia local instalada en el célebre Instituto de Enseñanza media, que vio llegar por primera vez a competidores, además jóvenes-, acabaría en la órbita de la universidad pública, y demostraría abiertamente, ya en 1975, que se había convertido en un reducto intelectual de la izquierda antifranquista. Las primeras intenciones tropezaron con el profesorado, fuertemente ideologizado - icómo no recordar aquí a los filósofos Pedro Arrarás y Aurelio Arteta, francamente marxistas, o al entrañable poeta Ramón Irigoyen?-, pero, todavía, realmente ajeno a cualquier preocupación por la historia de aquella provincia castellana. El conservadurismo local se presumía duradero, inmutable, y la autonomía regional ni se mentaba; el propio partido socialista de entonces, empeño juvenil de Javier Sáenz de Cosculluela, preconizaba la inclusión de La Rioja dentro de Euskadi, región que, por su combatividad antifranquista, despertaba las mayores emociones en la izquierda local. El compromiso del CUR no podía reducirse a la pequeña ciudad conservadora, magníficamente retratada por Bardem en Calle Mayor.

Cuadernos seguiría ajeno a la investigación histórica regional durante los próximos años. Todavía en 1980, en la edición de los índices de la revista, sus promotores declaraban como objetivo "dar a conocer las inquietudes investigadoras de un sector de la Universidad española y ampliar el conocimiento de una región científica y culturalmente marginada, como ha sido, como es, La Rioja". Para acabar como era habitual- se añadía un reclamo típicamente resistente: "En el futuro, si nos dejan, nuestros Cuadernos (...) no renunciarán a ninguno de los objetivos precedentes"4. El principal era, como se declara, ampliar el conocimiento entre los riojanos, pero todavía no el conocimiento del pasado de los riojanos. Eso interesaba menos que la labor de transformación social y política que los universitarios del Colegio se proponían desarrollar mediante su función docente y su consiguiente impacto externo. Probablemente, la Historia no era considerada todavía como palanca de transformación social, como proyecto social, concepto que en España no se desarrollaría tanto por asumir metodológicamente el marxismo, como por el impac-

2. Corona Baratech, 1975: "Sobre el tránsito del absolutismo al liberalismo", y Ferrer Benimeli, 1975: "Voltaire y la Masonería" (con lógica aplastante, catalogados, en 1980, en el área de Contemporánea, como todos los que, referidos al siglo XVIII, escribieron en Cuadernos los autores citados y el recordado Rafael Olaechea Albistur).

3. El enunciado no está falto de comprobación (aunque ésta no constituye nuestro objetivo). Libros como Luz a Ocón son una clara demostración de que el Caudillo y las glorias imperiales eran lo mismo.

4. Cuadernos de Investigación, Indices, Imp. Vidal, sin pie y sin año. El subrayado es mío. 
to político de las historias nacionales, elevadas a fundamento de las nacionalidades históricas del Estado por la izquierda ${ }^{5}$.

Hasta 1980, Cuadernos había publicado otros artículos, también de índole general, con contenidos dispares: la contribución española a la independencia de EE.UU. (Armillas), los motines de 1766 en varias localidades españolas (Corona), una sociología del bautismo en el XVII (Ansón), el motín de 1766 en Córdoba (Olaechea), etc. ${ }^{6}$ Pero, ya aparecían algunas referencias a la región, a la evolución histórica de su población - ¡los pioneros siempre los demógrafos!—: un artículo de Jesús Maiso y José Antonio Salas sobre la población de Huércanos y otro de Tomás Franco sobre la población de Logroño. El primero utilizaba ya los registros parroquiales, con una metodología todavía rudimentaria - más si la comparamos con la que han llegado a desarrollar luego los demógrafos-, pero digna; el del segundo era pura entelequia, el sentido común aplicado a una historia sin conocimiento de las fuentes más imprescindibles?.

Sin embargo, la historia regional existía. Probablemente, conocía en esos a ̃̃os una notable expansión, al calor del mismo fenómeno que había impulsado la creación del Colegio Universitario: la preocupación cultural de los recién llegados a la política provincial, que ya se preparaban, unos y otros, para los cambios políticos que el futuro necesariamente tendría que producir. Existía, seguía existiendo en la institución que la había amparado desde hacía décadas: el Instituto de Estudios Riojanos (IER) y su vehículo de expresión, la revista Berceo.

Como todos los institutos locales, el IER se prolongó inmutable mucho más que el régimen que lo creó ${ }^{8}$. Hasta entrados los ochenta, ejerció como sólido monopolio su papel de difusor de la cultura regionalista de tinte tradicional y de aglutinador de un grupo de presión reaccionario, sólo amenazado, muy tímidamente, por el reformismo centrista, inteligentemente diseñado por Julio Luis Fernández Sevilla, primer presidente de la preautonomía riojana. La combinación erudito local - IER y su sello nítidamente franquista era para los jóvenes universitarios del Colegio la bestia negra con la que ni siquiera se podía pensar en combatir. Sencillamente, se le ignoraba;

5. Hasta principios de los ochenta — pongamos como hito la aparición del libro de FONTANA, 1982, y su consiguiente difusión-, los historiadores jóvenes de izquierda que no estuvieran en contacto con los historiadores marxistas de las grandes universidades, tenían muchas dificultades para llevar a la Historia su compromiso idealista con el materialismo histórico.

6. ARMILLAS VICENTE, 1977: "El nacimiento de una gran nación..."; CORONA BARATECH, 1977: "Los sucesos ocurridos desde marzo a mayo de 1766 en Tobarra, Oviedo, Totana, Quesada y Lietor"; ANSÓN CALVO, 1977: "Sociología del bautismo en el siglo XVII" FERRER BENIMELI, 1978: "La Masonería bonapartista en Aragón"; OLAECHEA ALBISTUR, 1976: "El anticolegialismo del gobierno de Carlos III" y 1978: "Resonancias del motín contra Esquilache en Córdoba".

7. MAISO GONZÁLEZ y SALAS AUSENS, 1976: "La población de Huércanos (provincia de Logroño) (sic) según los registros parroquiales (1550-1700)" y FRANCO ALIAGA, 1979: "La población de la ciudad de Logroño desde el siglo XI al XVI".

8. Por lo que sabemos de otros institutos, la izquierda no dio la batalla por su control hasta los inicios de la década de los ochenta. Probablemente, el caso exitoso más temprano es del instituto Alfonso el Magnánimo de Valencia, que fue nuestro modelo. 
cuando más, se ridiculizaba semiprivadamente a los miembros de la anquilosada institución, a los que se tachaba de eruditos locales - gran pecado entonces para los historiadores universitarios - $\mathrm{o}$, sencillamente, de ignorantes casposos dedicados al localismo, incapacitados por su escasa preparación intelectual para acceder al conocimiento de las grandes corrientes de la Historia de la humanidad (o cosas parecidas).

Los jóvenes historiadores universitarios relacionarían el conservadurismo del IER con la historia local y regional, por lo que ésta adquiriría automáticamente tintes despectivos, los mismos con que se despreciaba lo que se denominaba positivismo (sin saber bien en que consistía el arma arrojadiza que podía ser lanzada contra cualquiera). Por eso, los Cuadernos del CUR tendrían un objetivo militante y universalista — "se pretendía, también, acoger trabajos científicos de otros profesores de universidades españolas y extranjeras", se declaraba todavía en 1980 - mientras, la revista Berceo, del IER, quedaba para los trabajos de eruditos locales y mantenedores culturales del régimen y el nacionalcatolicismo.

En efecto, Berceo seguía siendo una miscelánea de artículos dominada por la exaltación de los símbolos regionales más conservadores. El continuismo se apreciaba en el predominio de la historia eclesiástica, la exaltación de hidalguías y solares, el interés por el "rico pasado medieval", etc. Así, en 1975 se publicaba un ingenuo trabajo sobre la incidencia del solar de Tejada en Clavijo _todavía la aparición del Santo en Clavijo era una hipótesis histórica - y otro, sobre la heráldica de Lumbreras; uno, en el que un agustino recoleto se preguntaba por el pasado riojano de un abad de Silos, otro en que se exponía una rotunda "vida económica y social de la ciudad de Logroño en los siglos XVI y XVII" (presuntamente elaborado con el auxilio de confidencias de elevado origen, a juzgar por las fuentes utilizadas) y, en fin, una "Geografía Mariana de la Rioja" y un documento papal del XVII".

Los siguientes años del quinquenio no ofrecerían muchas novedades, a excepción de algunas contribuciones aisladas y azarosas que vendrían a introducir la dignidad en la revista y la diferenciarían, a pesar de todo, de las que editaban otros institutos provinciales. En el mismo año 1975, José Angel García de Cortázar publicaba veinticinco páginas espléndidas sobre la sociedad altorriojana en los siglos $\mathrm{X}$ al XIV; un año después, Jesús Baigorri presentaba el primer estudio analítico del catastro de Ensenada en una localidad de La Rioja, con nítido carácter economicista y aplicaciones estadísticas. Por primera vez en la historia de La Rioja se introducía el número y su comprobación, sustituyendo a las suposiciones y al dato aislado documental ${ }^{10}$.

9. HERNÁNDEZ LÁZARO, 1975: "El Solar de Tejada: una incidencia en Clavijo". (La revista que publicaba la Diputación Provincial se titulaba Clavijo; pasarían todavía varios años hasta que esa Institución dejara de celebrar la fiesta de Santiago con actos de exaltación histórica notoriamente extremista). RUIZ DE GALARRETA, 1975: "La heráldica de Lumbreras de Cameros, datos para la Historia"; PEÑA, 1975: "Rodrigo Iñiguez, Abad de Silos ¿Fue antes monje y prior de San Millán"; PALACIOS SÁNCHEZ, 1975: "La vida social y económica de la ciudad de Logroño en los siglos XVI y XVII"; ABAD LEÓN, 1975: " Geografía Mariana de La Rioja"; GARCÍA y GONZÁLEZ BLANCO, 1975: "Un documento papal del siglo XVII dirigido a la aldea de Navalsaz".

10. GARCÍA DE CORTÁZAR, 1975: "Introducción al estudio de la sociedad altorriojana en los siglos X al XIV"; BAIGORRI JALÓN, 1976: "Alberite en el siglo XVIII (Análisis del Catastro de Ensenada)". 
En lo que a la Historia Moderna se refiere, la gran excepción aparece al final del quinquenio con la publicación de I.A.A. Thompson de un artículo en el que ya la historia social de las multitudes es el factor principal de estudio, a pesar de que algunos conceptos son erróneos, como demostraría en su tesis doctoral P. Lorenzo Cadarso ${ }^{11}$.

Pero, por esos años, el IER desarrollaba un nuevo cauce de expresión, incrementando el número de publicaciones de su colección de libros denominada Biblioteca de Temas Riojanos. A diferencia de Berceo, que seguiría admitiendo cualquier colaboración de los miembros del instituto, la Biblioteca demostró durante este quinquenio una cierta responsabilidad al seleccionar las publicaciones. En la Biblioteca, vieron la luz obras de interés, que, en algunos casos, provenían de trabajos de investigación de universitarios - todavía no del Colegio Universitario de Logroño, por las razones antes expuestas-, y que, sobre todo, respondían a campos de investigación o técnicas novedosos que superaban el sentido común, única herramienta de los eruditos del viejo IER. Así, se abrirían paso los estudios de Arqueología, los de crítica literaria, etc. ${ }^{12}$; pero, sobre todo, los relativos a la Historia del Arte y a la transcripción paleográfica de documentos.

En estos dos últimos campos, destaca la labor del paleógrafo Ildefonso Rodríguez de Lama y del estudioso del arte Gabriel Moya. Tanto en este quinquenio como en el siguiente, la publicación de documentos en Colecciones Diplomáticas fue constante; no sólo Rodríguez de Lama, también Antonio Ubieto y Sáinz Ripa, entre otros $^{13}$, se sumarían a la tarea de publicar Colecciones Diplomáticas y transcripciones de documentos, con lo que los historiadores jóvenes empezaron a poder utilizar catálogos y las jóvenes instituciones políticas regionales descubrieron la existencia de archivos históricos eclesiásticos y civiles (interesarse por su conservación que todavía no debía de ser urgente, según parece).

Pero si la labor de los paleógrafos nunca pasó del empeño individual, el interés y la profesionalidad de Moya logró crear escuela y fomentar la divulgación del arte riojano, hasta el punto que llegaría a ser el campo más mimado en la etapa reformista. Realmente, el esplendido patrimonio artístico riojano de los siglos XV al XVIII había sido presa de un total abandono; sólo el culto y la exaltación de ciertos valores había preservado el conocimiento popular de algunas obras - San Millán (El Escorial de La Rioja), Valvanera (sede de la patrona), el castillo de Clavijo (restaurado) etc.-_,

11. THOMPSON, 1981: "El Concejo abierto de Alfaro en 1602: la lucha por la democracia municipal en la Castilla seiscientista": LORENZO CADARSO, 1992: La conflictividad popular en Castilla (ss. XVI y XVIII). Otro punto de vista en GÓMEZ URDÁÑEZ. y LORENZO CADARSO, 1993: "Las comunidades rurales frente al Estado Absoluto" y en ALONSO CASTROVIEJO, 1992: Problemática agraria y solución burguesa, Logroño, 1750-1833, en prólogo a cargo de Gómez Urdáñez,, en que se critica el punto de partida de Thompson sobre la debilidad del Estado en España.

12. Solo como ejemplo, mencionaré VV.AA., 1973: Miscelánea de Arqueología Riojana; MARCOS POUS, 1979: Trabajos arqueológicos en la Libia de los Berones, o GARCÍA TURZA, 1975: Matute y su léxico, 1. Labores agrícolas.

13. En los que respecta a la Historia Moderna es de interés SAÍNZ RIPA, 1979: Archivo de Santa María de La Redonda. Catálogo Documental, siglos XVI y XVII. Los otros catálogos son de documentación medieval. 
que sólo por ser gloriosos escenarios eran conocidas. Pero, además, el arte riojano era un campo aséptico y un excelente escaparate para los políticos reformistas. Con el tiempo, la difusión de "nuestro rico patrimonio" llegaría a crear un cierto entusiasmo autonomista en la región; hasta tal punto se insistió en la difusión del arte riojano, sobre todo por José Manuel Ramírez, discípulo de Moya, y durante un tiempo Director Regional de Cultura, que llegaría a convertirse, ya a fines de la década de los ochenta, en un banderín de enganche para un pequeño colectivo con aspiraciones culturales, que luego derivaría hacia el irredentismo regionalista político. Del conocimiento del magnífico pasado riojano a través de las obras de arte se pasaría a la constatación del abandono y la incultura del presente, con lo que se atizaría la reivindicación política regionalista y el reforzamiento de una señas de identidad en una Comunidad que, aun después de ser declarada autónoma, no podía encontrarlas en ninguna parte.

No cabe duda de que, cuando Moya publicaba su Enciso Monumental o comenzaba el Catálogo Monumental de La Rioja, con un pléyade de colaboradores, o Ramírez publicaba su Miguel Angel de La Redonda ${ }^{I 4}$, no había más que un interés profesional y una vocación que les llevaría a realizar un enorme trabajo de archivo, así como una clara conciencia del abandono en que se encontraba el patrimonio. El constante trabajo de Ramírez, Ruiz Navarro, B. Arrúe, y otros más tarde, sería bien recibido en la nueva etapa en la que iba a entrar el IER, la que marca los primeros pasos del gobierno autónomo.

En cuanto a la Historia Moderna, el quinquenio había sumado algunos libros de factura muy desigual. El sacerdote Felipe Abad León, Cronista Oficial de La Rioja, publicaba en 1975 un estudio de la guerra de la Independencia en Arnedo con el más puro estilo documentalista - lo que incluso figura en el título del libro-, sin conocimientos bibliográficos y sin aportar demasiado a los estudios sobre el tema, entonces bastante abundantes. En 1978, volvía a la Biblioteca de Temas Riojanos con un texto sobre Logroño según el catastro de Ensenada ${ }^{15}$. Probablemente, el mejor texto para los modernistas es el Fernández Marco (1976) sobre Briones, un buen intento de historia total de una localidad, con gran aparato de datos de los archivos locales. Al margen de los canales habituales, se editaba un libro en la ciudad de Arnedo, que pretendía ser unos apuntes para la historia de Arnedo, con prólogo de F. Justo Pérez de Urbel, y explicaciones previas del autor, el cronista oficial de Arnedo, Fernando

14. También por poner algún ejemplo, MOYA VALGAÑÓN y RUIZ, 1975: Enciso Monumental; RAMÍREZ MARTÍNEZ y SÁINZ RIPA, 1977: El Miguel Angel de La Redonda; MOYA VALGAÑÓN, 1980: Arquitectura religiosa del siglo XVI en La Rioja Alta.

15. ABAD LEÓN, 1975: Arnedo y su comarca durante la guerra de la Independencia. Estudio documental y 1978: Radiografía histórica de Logroño a la luz del catastro del Marqués de la Ensenada. (Obsérvese la incorporación de la técnica médica a la Historia en la Radiografía histórica...). Alonso Castroviejo descubriría algunos errores de importancia en este texto al realizar el análisis del catastro para su tesis doctoral. No obstante, hay un "acierto" sorprendente. Para conocer el peso de la propiedad eclesiástica sobre la seglar, Abad cuenta el número de libros dedicados a una y otra: tres a la primera y cinco a la segunda. Así obtiene la proporción 3/5, muy aproximada a la real. Cfr. ALONSO CASTROVIEJO, 1992: Problemática agraria, solución burguesa, Logroño, 1750-1833. Con todo, historiográficamente, es la obra más digna de Abad León. 
Fernández de Bobadilla (1976), cargadas de disculpa y honestidad. El texto es un compendio de notas, algunas con referencia documental, sobre temas tan variados como la Sismología, la Fauna, la Geología, la Paleontología, el arte, etc. Es de interés su sorpresa al encontrar un caso de parroquialidad no territorial en Arnedo y declararlo "único en el mundo", cuando también las parroquias del cercano Logroño, por ejemplo, eran de libre adscripción.

Con todo, y para concluir, el quinquenio 1975-1980 había producido algunas novedades, que se mostrarían en su pleno desarrollo unos años más tarde. Hacer historia seguía siendo una distracción erudita para la sociedad bienquista de La Rioja; para los jóvenes universitarios del Colegio, seguros del futuro, empezaría a ser un asunto profesional y, con un poco de petulancia comprensible, una disciplina científica. El marco político se abría: la democracia demostraría pronto que era necesario rehacer la Historia de España y las autonomías iniciarían su justificación histórica. A pesar de las dudas y las vacilaciones, la Historia sería un instrumento excepcional en la nueva época.

Con todo, fueron años de penitencia para el historiador novel; había pocos libros, no sólo en Logroño, sino incluso en las bibliotecas de los departamentos de la Universidad de Zaragoza; se ponían mil obstáculos al acceso a los archivos, los más desatendidos y sin catalogar - el del ayuntamiento de Logroño podría ser en aquellos años un ejemplo de la desidia general - y hasta había que explicar de mil maneras qué es lo que se quería investigar ante los ojos de sorpresa de algún cura o funcionario municipal, que no acertaba a comprender nuestras intenciones y menos su utilidad. Los becarios de investigación de entonces conservan un verdadero arsenal de anécdotas curiosas sobre su tránsito por los archivos.

\section{AÑOS DE FRUSTRACIÓN, 1981-1985.}

La autonomía y el despegue de la economía española fueron los factores más importantes sobre los que se apoyó el primer impulso de la historia regional; la primera, porque volcó la actividad política de todos los partidos al apoyo de proyectos de índole regional -entre los que el conocimiento del pasado con una concepción más acorde a los tiempos empezó a despertar algún interés-; el despegue, porque permitió iniciar una política de subvenciones y un incremento del profesorado universitario y del número de becas de investigación destinadas a la formación de investigadores. El Colegio Universitario atravesaba una crisis de financiación, agravada por la desconfianza que inspiraba a la derecha regional en el poder una institución que no podía controlar salvo con la yugulación presupuestaria; la crisis pondría en peligro la propia existencia del Colegio. No obstante, este es el periodo en que, a pesar de las dificultades, la institución lograría afianzarse y alcanzar el suficiente desarrollo que luego le permitió integrarse en la Universidad de Zaragoza. En 1981 se concedía una plaza de Historia Moderna, área que había sido mantenida sin pro- 
fesor durante unos años, desde que Jesús Maiso, su anterior titular, obtuviera plaza en la Universidad de Santander.

La ausencia de profesorado, por una parte, y el atractivo que, como hemos dicho, despertaban otras áreas, se unía a la predilección que los eruditos locales parecían tener - como ocurría en toda España- por los siglos XVI al XVIII ${ }^{16}$. La Edad Moderna era un periodo de esplendor y decadencia, de luces y sombras, un amplio espacio temporal que permitía presentar las glorias imperiales y los logros del virtuoso pueblo castellano y, a la vez, penar lacrimósamente por su derrota, justificando en el pasado el mito de los enemigos de España, tan caro a los jerarcas de la España aislada, odiada y envidiada; nadie lo haría mejor que Felipe Abad León en su biografía del marques de la Ensenada, el gran impulsor de la marina, contra el que conspiró la pérfida Albión hasta lograr la caída del singular ministro riojano, para adueñarse de nuestras queridas Américas ${ }^{17}$.

La Historia Moderna siguió una vida lánguida; los eruditos del IER andaban un tanto desanimados ante los cambios que sabían acabarían por afectar a su querido instituto y, además, no podían competir con las áreas nuevas, que estaban en pleno desarrollo, impulsadas por algunos investigadores jóvenes que la etapa reformista de Julio Luis Fernández Sevilla lograría atraer al Instituto. Era la "savia joven" que vendría a recoger el testigo dejado por los veteranos, tal y como estos lo expresaban: como si fuera la ampliación de una cofradía. La reforma de Fernández Sevilla no pretendía en realidad más que eso: una ampliación del número de miembros del IER, a base de atraer a jóvenes investigadores como J.M. Ramírez y, sobre todo, a algunos profesores universitarios del Colegio, a quienes convenía tener dentro, aunque, sin duda, lejos de los cargos y sin posibilidad de control alguno sobre la política presupuestaria del IER que, al calor del regionalismo creciente, se iba a ver muy favorecida. La prueba de fuego de que la reforma no iría más allá se produjo en los forcejeos que acompañaron al fallo de un premio a la investigación que dejaría fuera un libro de Francisco Bermejo sobre La Segunda República ${ }^{18}$.

16. Las razones ideológicas de esta predilección no son otras que el intento de encontrar en el pasado una justificación del imperio español, tan caro al Caudillo y al reaccionarismo español. Cfr. VALLS MONTÉS, 1984: La interpretación de la Historia de España y sus orígenes ideológicos en el bachillerato franquista, 1938-1953. Ante libros como éste o como, por poner un ejemplo regional, el de HERNÁNDEZ GARCÍA, 1984: La represión en La Rioja durante la guerra civil, especialmente su apéndice 2, t. 3, p. 157 y ss. sobre la brutal represión de los enseñantes, El florido pensil, de G. Sopeña, éxito de ventas de la editorial Crítica, es un monumento a la superación mediante el humor — por cierto, magistral — de las nauseas que provoca el conocimiento - y la experiencia - de la represión cultural franquista.

17. Felipe Abad dedicó al marqués de la Ensenada dos trabajos; uno, un folleto divulgativo refería interesantes anécdotas supuestas de la infancia del marqués, como verlo corretear con los monaguillos en Santo Domingo de la Calzada, después de dejar claro, tras arduas investigaciones, que D. Zenón "fue natural de Hervías, pero nacido en Alesanco", con lo que nos quedamos todos pasmados. José Luis Gómez Urdáñez escribiría un artículo en el periódico local, La Rioja, ridiculizando tan despropósito con la canción de Machín "dos mujeres a la vez". ABAD LEÓN, 1985: El marqués de la Ensenada, su vida y su obra. También sobre el marqués, publicaba una obrita un maestro polígrafo riojano, MANZANARES, 1982: El marqués de la Ensenada, estadista universal.

18. BERMEJO MARTÍN, 1984: La Segunda República en La Rioja. Elecciones y contexto político. Con todo, el libro se publicó dos años después, tanto por el interés del socialista Pérez Sáenz Consejero de Cultura 
En el otro lado, el Colegio Universitario, que empezaba su expansión, iniciaba una dinámica de impulso de jóvenes investigadores y de preparación de los curricula de quienes ya entreveían que tendrían que opositar: el inmediato proyecto era, para unos, hacer la tesis; para los que ya la tenían, investigar y publicar; y, para una minoría, además, dirigir tesinas y tesis. Pero se producía una paradoja: el CUR tenía medios humanos para acometer la empresa intelectual, pero no tenía dinero ni posibilidad de llegar a subvenciones destinadas a la investigación, mientras que el IER, por el contrario, veía crecer su presupuesto y lo distribuía ampliamente entre sus selectos seguidores, viejos aferrados al privilegio y jóvenes universitarios "permitidos", provocando la crítica airada entre los desafortunados en el reparto. Era evidente que el asalto al IER se iba a producir en breve.

El triunfo en la elecciones regionales del PSR-PSOE iba a precipitar la solución; además, ésta se produciría de forma realmente rupturista. El Consejero de Cultura socialista nombró en 1984 una comisión provisional integrada por J.M. García Ruiz, J. Ruiz Navarro, M.J. Barber y J.L. Gómez Urdáñez, con la colaboración de F. Bermejo, R. Fernández Aldana, efímero consejero del primer gobierno socialista, y, sobre todo, impulsada por el director General de Cultura, el entonces prosocialista José Manuel Ramírez. A este grupo se encargó la reforma del Instituto. Su primer trabajo consistió en redactar unos estatutos, en los que se imponía como requisito para ser miembro del IER la obligatoriedad de presentar a la Comisión un proyecto de investigación; ante las dificultades, los miembros del viejo IER desistieron (éste era el principal propósito). Pero, lo decisivo del periodo provisional no fue tanto producir el abandono de los viejos miembros, que casi no se resistieron, como iniciar la política de becas, destinadas a los jóvenes licenciados cuyas tesis estaban siendo dirigidas por los profesores del Colegio Universitario y reorientar la política de publicaciones, filtrándolas por los nuevos dirigentes de la Institución. Estos, tras el periodo provisional, serían además profesores del CUR, igual que su director C. Pérez Arrondo. Así se montó el trampantojo, que ha durado hasta hoy, por el que la opinión pública - y tristemente, algunos dirigentes políticos - confundían a ambas instituciones, sin que llegara a transcender que lo que en realidad ocurría es que una minoría del profesorado del Colegio Universitario había puesto a su servicio al renovado instituto, ejerciendo un férreo control monopolista, que sólo la llegada de la Universidad, ocho años después, contribuiría a desmontar.

Pero, esto ocurría al final del periodo y sus resultados se verán después. Hasta entonces, en el "entorno intelectual" del IER dominó la continuidad de lo que al final del periodo anterior ya se anunciaba: desarrollo de áreas asépticas atractivas —el

\footnotetext{
del primer gobierno socialista, que lo consideró un símbolo, como también por la clara determinación de Fernández Sevilla — probablemente apoyado por el joven e ilusionado investigador Juan Carlos Bilbao-, que se fijó ante todo en el valor del libro. Lo sorprendente es que el trabajo había sido dirigido por un catedrático de Madrid tan poco sospechoso como Seco Serrano y que, para entonces, había ya libros en circulación sobre el holocausto riojano en la guerra civil, mucho más reveladores. El IER, que vivía ajeno a estas manifestaciones de rojerio, sólo quería preservar su querido instituto.
} 
arte; todavía incipientemente la arqueología y la antigüedad ${ }^{19}$-; connivencia con los viejos autores y temas, que todavía se asomaban a Berceo pero ya no a la Biblioteca de Temas Riojanos, salvo alguna rara excepción; publicación de catálogos de documentos - con un desarrollo similar al de la Historia del Arte-y, como es lógico, cada vez más presencia de trabajos procedentes de la investigación desarrollada por universitarios (como en el periodo anterior, todavía no del Colegio Universitario de La Rioja). Sin embargo, se produce una novedad interesante: llegan a las prensas del IER los primeros trabajos de ciencias, una prueba de la apertura producida por el reformismo en la institución, tradicionalmente consagrada a las letras.

Para la Historia Moderna, el quinquenio representó un cierto abandono. Probablemente, los nuevos tiempos iban relegando aquel estilo tradicional que contrastaba vivamente con la difusión de la nueva historia de España y, sobre todo, con la nueva forma de hacer historia. Era evidente para todos que la Historia tenía también ya sus profesionales. Y que, como habían puesto de manifiesto el libro de $\mathbf{F}$. Bermejo o la visita a Logroño de Tuñón de Lara, por poner algún ejemplo, la izquierda reconquistaba el territorio del historiador, arrebatado por el régimen y sus postrimerías durante décadas. Por si fuera poco, el CUR organizaría en este periodo dos congresos sobre Historia de La Rioja, todavía denominados Coloquios a causa de una explicable timidez.

Berceo acogería todavía un artículo de J.M. Palacios Sánchez sobre los aspectos históricos de los recursos naturales de Cornago, de difícil interpretación, pero ya no se verían más Geografías Marianas; por el contrario, los hermanos Cantera Montenegro publicaban un trabajo sobre pleitos por la jurisdicción a fines del XV y otro sobre Inquisición en el XVI ${ }^{20}$, y en la Biblioteca veía la luz un libro que introducía la dignidad en el tratamiento de temas modernistas: un trabajo de José Luis Ollero de La Torre (1981) sobre el obispo Aguiriano. No mucho más dio de sí el periodo en el Instituto, quizás porque, como veremos, había otros proyectos.

El más importante fue la Historia de La Rioja, publicada por la Caja de Ahorros de La Rioja. La entidad respondía con este proyecto, tan generoso como mal encaminado, a la demanda de una historia de la joven región autónoma. Le encargó la dirección a Justiniano García Prado, viejo profesor de instituto y preclaro miembro del IER, que había despuntado por riojanizar al Reino de Pamplona-Nájera en un intento que acabaría en una concepción de esa ciudad como capital de un pretendido Imperio de Nájer $a^{2 l}$. A toda prisa se contrató a los colaboradores, a los que se exigió una celeridad inusitada. La obra, que podía haber sido un primer intento serio de

19. Durante el quinquenio, Berceo contiene hasta 14 artículos relativos al Arte en La Rioja, y la Biblioteca de Temas Riojanos, 6 libros. Cuatro artículos y dos libros pertenecen a J.M. Ramírez.

20. CANTERA MONTENEGRO, E., 1982: "Inquisición de Logroño: Sambenitos del siglo XVI" y CANTERA MONTENEGRO, M., 1985: "Pleitos por términos del concejo de Logroño, 1475-1495".

21. En realidad, J. GARCÍA PRADO era el mejor ejemplo vivo de los catedráticos del régimen. Su pensamiento había evolucionado muy poco después de la publicación de su interesante manual, 1951: Historia de la Cultura, cuarto curso. 
hacer historia regional — y de reconocer las carencias y la necesidad de emprender la investigación con otros medios- se transformó en una miscelánea, puro reflejo de la situación: lo nuevo y lo viejo convivían inexplicablemente. La sincera honestidad de los noveles que se veían sin medios y sin tiempo y la soberbia de la veteranía, que simplemente debía refundir escritos de los últimos cuarenta años, sin excluir ciertas colaboraciones de una y otra parte, que se solucionaron refundiendo manuales con dudosa pericia, produjeron una obra extraña y sorprendente. La Historia Moderna fue un claro ejemplo de todo lo anterior (el que suscribe, autor de varios capítulos, se incluye en todos los supuestos posibles). Probablemente no añadió nada a lo conocido, a pesar de colar algunas buenas intenciones. Sí es de destacar la colaboración de M. de Las Rivas sobre la cultura en la edad Moderna, sin duda lo mejor de la obra.

Lo más destacable de la empresa está fuera del libro, en el tenso ambiente que se notaba entre los colaboradores, las instituciones, las ideologías. El riojanismo simbolista, de medallita de la virgen de Valvanera, se estaba acabando cuando la derecha no había logrado enganchar todavía al regionalismo político; era demasiado aldeano: la frase con la que J. García Prado comienza la Historia de La Rioja es muy significativá: "La Rioja es Rioja desde que el mundo es mundo". Luego venía un capítulo de geología... ¡Y eso que todavía no se habían difundido las riojanas huellas de los dinosaurios de Enciso!

En 1982, el Colegio Universitario había logrado realizar con relativo éxito el I Coloquio de Historia de La Rioja, cuyas actas serían publicadas en la revista Cuadernos. El Coloquio era una exhibición de la Institución, que había salido de la crisis, y un desafío en el que los universitarios trataban de demostrar que la Historia era cosa de profesionales. La Historia Moderna y la Contemporánea compartieron todavía ponencia, reuniendo 26 artículos. La mayor parte procedían de investigadores de la región; algunos se daban a conocer casi con el Coloquio; pero ya había algunas comunicaciones de profesores de fuera y — lo más novedoso- de otros distritos que el zaragozano. Así, destaca la magnífica colaboración de Pedro Carasa Soto sobre la beneficencia en el Antiguo Régimen, primicia de lo que sería su tesis doctoral, la de A. González Enciso, sobre la industria dispersa en Cameros, fleco de su trabajo sobre la fábrica de paños de Guadalajara, y la de M.A. de Bunes sobre la incidencia de la Real Fábrica de Ezcaray en la demografía de la villa ${ }^{22}$. También destacan, ya entre los autores de aquí, los artículos de demografía de M. Lázaro y P. Gurría que iniciaban en ese tiempo su prolífica obra sobre demografía de la región ${ }^{23}$ y la colaboración de A.

22. Todos los artículos de Moderna del I Coloquio están en Cuadernos de Investigación, 1984. CARASA SOTO: "Crisis y transformación de la beneficencia del Antiguo Régimen. Aproximación al sistema hospitalario de La Rioja entre 1750 y 1907"; GONZÁLEZ ENCISO: "El concepto de "provincia" en el Compendio Historial de la Provincia de La Rioja del P. Matheo de Anguiano"; De BUNES IBARRA: "Incidencias de la Real Fábrica de Paños de Santa Bárbara y San Carlos y la explotación minera en la demografía de Ezcaray en la segunda mitad del XVIII".

23. LÁZARO RUIZ, 1984: "Torre en Cameros: la movilidad de población en un núcleo de montaña durante los siglos XVII y XVIII"; LÁZARO RUIZ y MARTíN MARTÍN, 1984: Demografía histórica: Metodología para ordenadores aplicada al sistema de reconstrucción de familias en los Cameros durante los 
González Blanco (1984), quien animó a los universitarios y colaboró activamente, no sólo en su campo de investigación. Como no podía ser menos, uno de los altos cargos del IER se atrevería a contrastar su ciencia en el entorno de la Universidad, con una piadosa recreación religiosa del ambiente religioso con motivo del cólera de $1885^{24}$.

Mientras, Cuadernos seguía la tónica habitual. Sólo un artículo sobre historia Moderna vería la luz en estos años y, de nuevo, con autor y temática aragoneses ${ }^{25}$. En la misma linea, el profesor de historia Moderna del CUR defendía en 1982 su tesis sobre marginación social en el siglo XVIll...pero todavía en Aragón (Gómez Urdáñez, 1982).

El II Coloquio sobre Historia de La Rioja, celebrado en octubre de 1985 es el hecho fundamental del periodo, tanto en lo relativo a la organización como en el impulso que sufriría la Historia Moderna. Organizado por el CUR con la colaboración del gobierno regional socialista, presentado e incentivado por su presidente José María de Miguel, fue un verdadero hervidero de novedades. Al contrario que el I Coloquio, todas las áreas prepararon con tiempo las ponencias, que se encargarían a profesores de otras universidades; a la vez, se impulsaba la participación de investigadores desde una eficaz organización general. En Moderna, se encargó la ponencia a Francis Brumont, que iniciaría desde entonces una fructífera relación con los modernistas riojanos. Conocido sólo por las referencias a La Rioja en sus publicaciones (F. Brumont, 1978 y 1984), Brumont presentó una ponencia repleta de sugerencias (Brumont, 1986); sin duda, después de su intento de historia total en la ponencia y de la diversidad de las comunicaciones, no habría otro remedio que pasar a la fase de historia analítica (Gómez Urdáñez, 1986 a). Durante algunos años, primaría el espíritu Annales que este discípulo de Bennassar nos había transmitido.

El II Coloquio fue la gran ocasión para conocer a otros historiadores; algunos como Angeles Cristóbal Martín (1986) o Luis Enrique Rodríguez San Pedro (1986) volverían a colaborar en proyectos regionales después de dar a conocer en sus comunicaciones sus proyectos de investigación: tanto la Inquisición como la historia de la universidad eran campos poco o nada tratados en la historiografía riojana y en los proyectos de investigación que se iniciaban por esas fechas. Otras comunicaciones giraban en torno a problemas más conocidos; por ejemplo, P. Gurría volvía a presentar un artículo sobre demografía (1986) mientras M. Lázaro abandonaba por una vez las cuentas de la vida y la muerte y su permanente colaboración con Gurría, y

siglos XVII y XVIII"; GURRÍA GARCÍA, 1984: "Observaciones sobre la estructura familiar camerana en la época Moderna". En el año 1982, M. Lázaro y P. Gurría habían publicado un artículo conjuntamente, con lo que iniciaban una estrecha colaboración: LÁZARO y GURRÍA, 1982: "La crisis de mortalidad de 1631 en La Rioja".

24. ABAD LEÓN, 1984: "Ambiente religioso creado en La Rioja a raíz del cólera morbo de 1885". En realidad, el padre Abad sólo describe algunos actos litúrgicos, confundiendo — una vez más- los sentimientos religiosos con los aparatosos actos de la liturgia católica.

25. RAMÍREZ COMPES, 1982: "Conflictos fronterizos en los valles franceses y aragoneses del Pirineo en el siglo XVIII". 
escribía sobre problemas de cultivos y propiedad (M. Lázaro, 1986). Ojeda San Miguel, quien seguiría colaborando especialmente en Cuadernos...Brocar, presentaba un trabajo sobre la Sociedad Riojana de Amigos del País (1986); Sáinz Ripa, de nuevo, un trabajo sobre historia eclesiástica (1986); Zuloaga Rada dedicaba su comunicación a la emigración riojana a América con fuentes del archivo de Indias (1986), etc. En cuanto al personal de la casa, Gómez Urdáñez presentaba su primer trabajo de temática riojana: las reacciones populares durante la guerra de Sucesión (Gómez Urdáñez, 1986b)

A pesar del notable éxito, al finalizar del II Coloquio, ya se podía prever que no habría otro. Las diferentes áreas se iban a desarrollar con independencia, en paralelo al fenómeno de hiper-especialización cronológica que existía en la historiografía española; y además, el Coloquio había demostrado grandes diferencias conceptuales y metodológicas entre el profesorado organizador, que se dividiría a causa de los diferentes objetivos, científicos y políticos, que perseguía. El IER renovado apuntaba ya como patrocinador único de la difusión de la historia regional y como gran fuente de subvenciones, pero también como monopolio dirigido antes a facilitar el escaparate político que a desarrollar objetivos universitarios. Las ilusiones de una minoría muy activa en la transformación del Instituto un año antes, que propugnaba el "uso" del IER como "laboratorio" del CUR, se vieron frustradas al ser relegada - en una rara maniobra animada por el Consejero de Cultura, Pérez Sáenz- por oportunistas que, presentándose con un falso discurso, copiado de los ingenuos idealistas de la ruptura el 84, utilizarían el IER en su sólo beneficio personal. Sólo los estatutos moderaron en algunos puntos la situación, sobre todo en la política de becas; el tiempo demostraría pronto que la composición de los tribunales que adjudicaban las becas, que, conforme a los estatutos, contaban con un catedrático de la Universidad de Zaragoza, fue un instrumento de control y de justicia, sin el que muchos becarios no hubieran sido seleccionados. Por esto, entre otras razones similares, los estatutos serían pronto considerados un estorbo. Desgraciadamente, algunos catedráticos zaragozanos, considerados la "gauche divine" universitaria, dejarían ver en estos tribunales su lado vulnerable: para nosotros, realmente heridos, sus "errores" no podrían tener ya otra explicación que la de la doble faz. De este argumento saldrían posturas que enlazan con las tópicas que en la Historia de España explican la ruptura de la izquierda a causa de veleidades personales y falta de compromiso de sus élites.

Pero, con todo, el IER hizo posible en este periodo que varios doctorandos tuvieran una beca de similares características a las de F.P.I. (sólo a causa de la negligencia del Consejero de Cultura y de los sucesivos directores del Instituto no se homologaron). Para la Historia Moderna iba a empezar una etapa de esperanza en medio de la frustración. Alonso Castroviejo, que había iniciado su tesina, sería becario de la primera promoción del IER; su tesis iba a ser la primera sobre Historia Moderna de La Rioja (publicada en 1992). En la siguiente etapa le seguirían varias. 


\section{AÑOS SIN EXCUSA, 1985-1990}

1985 marca el principio de la consolidación de las dos instituciones, IER y CUR, desde las que se impulsaría la Historia hasta cotas nunca conocidas en La Rioja. El Colegio Universitario, que se integraría en la Universidad de Zaragoza, obtenía respaldo externo y condiciones de seguridad para el profesorado, mediante el acceso de éste a los cuerpos estatales; su integración en los departamentos universitarios de Zaragoza permitiría el contraste científico de su trabajo al margen de los azares aldeanos y supondría una cierta protección para los menos afortunados en el reparto de la tarta de prestigios que todavía se hizo durante un tiempo en el IER, ahora, ya incomprensiblemente - ¿ceguera política o abandono?-, protegido, "incluso en sus errores" —sé que cito conscientemente a Besteiro- por el gobierno socialista. A pesar de la precariedad económica que supuso la integración, fueron años de cierto entusiasmo, a veces un poco artificial. Cuadernos se reformó, se inició una tímida política de publicaciones — por la que vio la luz un sabroso librito de Olaechea (1985) —, aumentaron las tesis dirigidas por el profesorado universitario; pero, sobre todo, se produjo una constante actividad externa, mediante la proliferación de ciclos de conferencias y presencias en Logroño de grandes historiadores. El profesorado se daba a conocer y, a la vez, conocía a los grandes investigadores (todo hay que decirlo: algunos visitantes estarían en los tribunales de acceso a la funcionización). Los Modernistas tuvieron la ocasión de conocer a Benassar, Soubeyroux, Tuñón de Lara, Brumont, Berthe, García Cárcel, Contreras, García Sanz, Fernández de Pinedo, T. Egido, Olaechea, etc., además de a los colegas de Zaragoza, Salas, Colás, Pérez Sarrión, Fernández Clemente, etc. Algunos visitantes iniciarían una colaboración que fue de importancia, sobre todo para los doctorandos ${ }^{26}$.

El Instituto de Estudios Riojanos también impulsaba sus dos publicaciones, la revista Berceo - de la que desgajaba Zubía, para temas de Ciencias- y la Biblioteca, diversificada en diferentes bloques, que supondrían casi una prolongación de los departamentos en que el IER había sido dividido; en la práctica, vendrían a ser el vehículo de difusión de los trabajos realizados en ellos y sólo y exclusivamente por ellos. La proliferación de algunas áreas es la mejor muestra del monopolio ejercido por los directores, en algunos casos, en beneficio de la difusión de temas de gran interés científico y de la promoción de excelentes investigadores, pero, en otros, a causa de un verdadero veto sobre el trabajo de los que se colocaron en la Oposición. En el caso de la Historia, el triunfo de la arqueología y el arte sería rotundo: todas las publicaciones de la serie Historia —once libros- se dedicaron a la Historia Antigua y a la Arqueología ${ }^{27}$, mientras los trabajos de otras áreas veían la

26. Fue importante para el equipo de modernistas que iba formándose en Logroño, por ejemplo, la ayuda de A. García Sanz o J. Contreras a los trabajos de J.J. Alonso Castroviejo o P. Lorenzo Cadarso; también el constante apoyo de J.A. Salas a M. Lázaro y P. Gurría, los demógrafos universales de La Rioja. Destacable es la colaboración de aprendizaje de José Luis Gómez Urdáñez con el maestro Tuñón de Lara, con quien prepararía una selección de textos para el volumen XII de su Historia de España, durante un periodo inolvidable de frecuentes visitas a su casa en Donostia.

27. Cfr. I.E.R., 1994: Catálogo de publicaciones, 23-24. Es obligatorio señalar que de los once libros, cinco son obras sobre arqueología en colaboración con C. Pérez Arrondo, el director del IER durante este periodo. 
luz en la vieja Biblioteca y en la colección Logroño, en una escasísima representación, ya que incluso ahí volvían a aparecer los temas predilectos del monopolio y -como no- los restos del pasado en forma de colecciones diplomáticas y tesis doctorales rescatadas de años atrás, a veces de muy dudosa factura ${ }^{28}$. Mientras, trabajos de gran interés, contrastados en la Universidad, se veían marginados, ocultados, por el rígido veto. Es el caso, por ejemplo, de la tesis doctoral de J.J. Alonso Castroviejo, defendida en 1989, que, a no ser por la iniciativa del Ayuntamiento -la colección Logroño se financia con fondos municipales - seguiría inédita, como están, desgraciadamente, otras de Historia Moderna y de otras áreas.

A pesar de todo, el periodo fue el más fructífero para la investigación histórica en La Rioja. Las becas y ayudas del IER y de otras instituciones impulsaron un nutrido grupo de doctorandos, aunque, en el lado oscuro, se desaprovechaba una buena idea del Instituto: los planes de investigación. El primer plan se titulaba "Bases estructurales de la Edad Media a nuestros días" y no tuvo resultados a pesar del dinero que se le inyectó, sin duda, a causa de la exclusión del proyecto de becarios e investigadores no implicados —o en abierta confrontación — con la dirección del IER. Fue sustituido, sin presentar explicación alguna, por otro que intentaba realizar un episcopologio calagurritano, que, en realidad era el trabajo personal del director del Departamento de Historia, el clérigo y profesor Eliseo Sáinz Ripa.

La renovación de métodos, la introducción de la teoría como soporte de la investigación y la creación de equipos estaría, desde entonces, apoyada exclusivamente por la Universidad en La Rioja. El primer trabajo que se inicia así en la comunidad es el de J.J. Alonso Castroviejo en 1985. La transición al capitalismo constituía un problema teórico antiguo, que a España llegaría con retraso, pero que fundamentó un corpus excelente de trabajos, teóricos y empíricos. El primer objetivo de Alonso fue aplicar las ideas a la documentación y lanzarse a la reconstrucción de la transición en Logroño, entre 1766 y 1833, el tema de su tesis de licenciatura. El excesivo esquematismo y la frenética búsqueda de elementos políticos - las crisis anunciadoras del estallido final - en una ciudad como Logroño nos llevó a un enorme desconcierto: las forzosas crisis a la manera de Franco Venturi en su magistral Settecento Riformatore no existían. Menos aún las contradicciones que, desde un marxismo verdaderamente catequístico, habíamos buscado como gran contribución al método. Solo 1801, el año en que caen los regidores perpetuos, se presentaba, al fin, como un primer ensayo de la clase liberal. Es seguro que lo explotamos excesivamente. Tendría que llegar P. Lorenzo Cadarso para apartarnos del marxismo naif. Nunca olvidaré el día en que Lorenzo dijo: dejé de ser marxista el día que vi el primer docu-

28. Así, por ejemplo, LÓPEZ DE SILANES y SAÍNZ RIPA, 1985... Colección diplomática calceatense, 4 vols. Es curioso que volverían a aparecer libros de historia eclesiástica realizados por sacerdotes, como por ejemplo, ITURRIOZ MAGAÑA, 1987: Estudio del subsidio y excusado (1561-1808). Contribuciones económicas de la Diócesis de Calahorra y La Calzada a la Real Hacienda. El libro es sencillamente un monumento a la confusión. 
mento en un archivo. Luego, el estudiante zaragozano tuvo que explicar que clase de marxista dejó de ser ese día. Pero, nos convenció a todos.

Los objetivos en la tesis de Alonso habrían de ser otros: en realidad, las contradicciones no llegaban a estallar políticamente, pero estaban soterradas, como era evidente que así debía suceder en el Antiguo Régimen. Por tanto, había que buscar antes los problemas, no su expresión política, que es, sin embargo, lo que nuestra impaciencia - y exceso de teoría - exigía. El problema era la tierra, la propiedad, la contradicción entre la propiedad feudal y las expectativas de la nueva clase liberal: éste era el primer paso: analizar la problemática agraria y comprender la solución liberal del principal problema desencadenante. Así, los problemas políticos se verían de forma más clara, como finalmente demuestra la tesis de Alonso ${ }^{29}$.

En efecto, la tesis parte de un excelente análisis de las variables clásicas para afrontar los factores económicos de cambio y sus resultados políticos. A diferencia de lo que se podría pensar sin conocer la estructura económico-social de un pequeña ciudad castellana como Logroño, los cambios antes de 1808 son de una importancia reveladora de las contradicciones del proceso de crisis del Antiguo Régimen; dos tesis destacan en el trabajo de Alonso Castroviejo: una, el factor desencadenante de la crisis de comercialización del vino, producto monopolizado por la élite urbana que controlaba el poder desde hacía 150 años hasta 1801 (Alonso Castroviejo, 1991), y otra, corolario de la anterior, la importancia de la tierra desamortizada entre 1801 y 1814, que daría satisfacción a la demanda de tierra para el cultivo de cereales - contra el monopolio del viñedo, generador del jornalerismo y el hambre - y que lograría llevar al ayuntamiento al grupo de comerciantes y hacendados que dominarán en el futuro la política - primero afrancesada y luego liberal — de la ciudad ${ }^{30}$.

Mientras se iniciaban estos planteamientos, aparecían algunas obras muy dignas, fruto del trabajo de incansables outsiders: la tesis doctoral de $\mathrm{M}^{\mathrm{a}}$ Carmen Sobrón (1986) sobre la guerra de la Independencia en Logroño, iniciada al calor del impulso que el Departamento de Historia Moderna y Contemporánea de Zaragoza había intentado dar el estudio del tema en los años setenta y felizmente concluida después

29. Con todo, el trabajo de tesis de licenciatura representó un buen ejemplo de conjunción entre teoría y experiencia, así como una aportación decidida al debate sobre la transición. ALONSO CASTROVIEJO, 1986: La transición en Logroño, 1766-1833. La tesis por fin se ha publicado (1982). Un resumen con nuevas aportaciones del autor, en GÓMEZ URDÁÑEZ (coord,), 1995: Historia de la ciudad de Logroño, vol. IV. Un buen resumen sobre las aportaciones del Catastro, en ALONSO CASTROVIEJO, 1990: Logroño, 1751: Las respuestas generales del Catastro de Ensenada.

30. La mejor exposición sobre el proceso está en la reconstrucción de la actuación de los Santacruz, enriquecidos en la desamortización de Godoy, luego en la napoleónica, con evidentes fraudes, que luego emparentarán con Espartero, consolidando el conocido liberalismo riojano. Cfr. ALONSO CASTROVIEJO, 1995: "Los nombres del Liberalismo riojano: de Domingo Santacruz a Baldomero Espartero". Precisamente, la figura poco edificante de Domingo Santacruz, o la todavía menos de Llorente, enriquecido también en la desamortización napoleónica, dieron pie a las advertencias sobre el triunfo de la burguesía y la crítica sobre el concepto meliorativo de la Historia que se vierten en el prólogo a la tesis de ALONSO CASTROVIEJO, 1992 por Gómez Urdáñez. Un artículo en el que exponen los resultados cuantitativos de los cambios, según diferentes censos y reconstrucciones, ALONSO CASTROVIEJO, 1990: "Estructura socioprofesional en Logroño, 1751-1857". 
de muchos años; salvo algunas concepciones generales lastradas por el punto de partida, el libro es un encomiable esfuerzo, modelo de honestidad y contiene un enorme trabajo de cuantificación de las deudas de guerra del municipio, sin duda, lo mejor del trabajo. También de gran interés, es la contribución al estudio de la red hospitalera riojana que hizo $\mathrm{M}^{\mathrm{a}}$ Victoria Sáenz Terreros (1986) en un libro que nos recordó su magnífico espíritu de colaboración en el I Coloquio de Historia de La Rioja.

Por estos años, se iniciaban en la investigación Juan Luis Pastor Ocón y Eduardo Gámez. El primero culminaría una tesis de licenciatura sobre Murillo de Río Leza a finales del Antiguo Régimen, publicada unos años después. En ella, lo que interesaba era comprobar qué había pasado con el viñedo en un pequeño pueblo - muy abarcable para aplicar una técnica cuantitativa - durante la crisis del Antiguo Régimen, para luego proseguir el estudio en toda La Rioja. Sospechábamos ya lo que ahora está comprobado: tras un enorme incremento de la superficie plantada, al calor del aumento de la demanda de vino en el País Vasco durante el siglo XVIII, sobrevendría la crisis de comercialización y, una vez roto el equilibrio vid-cereal, la crisis social típica de los pueblos con gran dedicación al viñedo, que es lo que había visto Jovellanos al visitar La Rioja. Juan Luis Pastor realizaría un trabajo encomiable, pero, desgraciadamente, al poco se apartó de la investigación. Lo mismo le ocurriría a E. Gámez, quien comenzó a trabajar sobre el catastro de Ensenada, con el objetivo de emprender un trabajo sobre la propiedad eclesiástica. Ambos temas serían recogidos por Santiago Ibáñez, como tendremos ocasión de ver, y en lo relativo a las hipótesis sobre el viñedo, por Alonso Castroviejo ${ }^{31}$.

En 1986 se publicaba un libro colectivo que había costado un año de trabajo a un amplio equipo de investigadores. Encargado por el ayuntamiento socialista de Cenicero, se trataba de un verdadero proyecto social, la ocasión de devolver a un pueblo su historia, a la que tenía derecho, según decía el alcalde en el prólogo. Era la ocasión de hacer una historia total, que, a juzgar por el entusiasmo general que rodeó al proyecto, sería además leída popularmente. Colaboraron una decena de expertos, incluyendo los geógrafos J. Arnáez y J.M. García Ruiz, que iniciaban la obra con un estudio geográfico, en la mejor linea de la historiografía francesa. Sin duda, la parte más incisiva era la Contemporánea, a causa de la memoria de la República y la guerra, todavía muy viva en un pueblo tan castigado. Pero, la Edad Moderna - y es difícil hacer la crítica por ser el coordinador y uno de los autores el que suscribe este texto - tuvo una buena factura. Lo más desarrollado vuelve a ser la crisis del Antiguo Régimen, no tanto aquí por el interés que despertaba entre los modernistas riojanos, como porque el pueblo, no era nada antes de mediados del XVII; su desarrollo como pueblo grande en La Rioja se produce en el XVIII gracias al despegue del viñedo, que llegó a ser verdaderamente un monopolio y causaría crisis dramáticas hasta el siglo XX por la concentración de jornaleros, los tiempos

31. A este respecto, puede consultarse ALONSO CASTROVIEJO, 1992 y el capítulo sobre la Junta de Cosecheros en GÓMEZ URDÁÑEZ, J.L (coord.), 1995. La tesis de licenciatura publicada de PASTOR OCÓN, 1989: Transformaciones económicas en Murillo de Río Leza, 1750-1833. 
muertos del trabajo en la vid y la presión sobre precios de la uva de los pequeños viticultores y sobre salarios de jornaleros sin tierra que ejercían los grandes propietarios y los bodegueros compradores. Los fenómenos de violencia volcánicos se producían desde fines del siglo XVIII en cuanto fallaba cualquiera de los factores sobre los que fluctúa el débil mundo de la comercialización del vino. Para el conocimiento de la economía riojana del Antiguo Régimen, Cenicero fue un eslabón importante que añadimos a los ya estudiados, Briones, Alberite, Murillo de río Leza; pronto podríamos incluir Logroño ciudad.

El mismo año 1986, se renovaba la revista Cuadernos. Se creaba un Consejo de Redacción, compuesto por el profesorado universitario de Historia, y un Consejo Científico, que acogía a investigadores de prestigio, en Moderna, Angel García Sanz, Francis Brumont, Bartolomé Bennassar y Rafael Olaechea. La revista se despiezaba en secciones que tratarían sobre problemas historiográficos de interés, agrupando artículos de variados planteamientos y procedencia: habría "temas riojanos" en la medida en que despertaran el interés de colegas de otras universidades y que éstos enviaran colaboraciones. Lo importante era el planteamiento de un problema general, no el pasado riojano. El proyecto funcionó con altibajos ${ }^{32}$, pero produjo algunos números con un cierto impacto extrarregional, que era uno de los objetivos. El área de Historia Moderna encontraría aquí casi la única posibilidad de difusión en La Rioja. El número de 1986 salía con un apartado monográfico sobre agricultura y ganadería, en el que Fernández Clemente, Gómez Urdáñez y Melón Jiménez (U. de Extremadura) escribían sobre la ganadería al final del Antiguo Régimen en España, La Rioja y Extremadura ${ }^{33}$; en el siguiente, dominaban dos temas: la Inquisición, con artículos de B.Z. Garmendia (U. de Toulouse-Le Mirail), R. Olaechea y M.A. Cristóbal (U.A.M.), y los concejos castellanos en la Edad Moderna. En éste, junto a las colaboraciones de Hiltpold (de la Universidad de Oklahoma), Brumont y Montemayor (de la Universidad de Toulouse), publicaban su primer artículo los doctorandos Alonso Castroviejo y Pastor, con lo que se cumplía uno de los objetivos pri-

32. El primer director de la revista renovada, el que suscribe, acabaría por dimitir ante las presiones del ya denominado grupo IER, que lograría colocar como director de la revista del CUR al director del mismo Instituto regional. La confusión entre una y otra institución se empezaba a reforzar por los intereses de la minoría del profesorado del CUR que dirigía y utilizaba el IER; de igual forma, aumentaba la tendencia al monopolio: el ex-director de la revista ni siquiera continuaría como miembro del Consejo de Redacción, en el que tradicionalmente, desde la fundación, estaban todos los profesores de las áreas históricas del CUR. Con todo, el siguiente número, el 13, y el 15, serían dedicados a Moderna casi en su totalidad, lo que en vez de ser una prueba del trabajo de captación del anterior director es prueba del abandono de quienes obtenían más beneficios al margen de las institución universitaria.

33. Cuadernos de Investigación, Brocar 12, 1986. (Brocar se añadió como homenaje al primer impresor de Logroño) Con temática modernista, FERNÁNDEZ CLEMENTE, 1986: "Sobre la crisis de la ganadería española en la segunda mitad del XVIII", GÓMEZ URDÁÑEZ, 1986: "Subsistencia y descapitalización en el Camero Viejo al final del Antiguo Régimen", MELÓN JIMÉNEZ, 1986: "De Cameros a Extremadura. Historia y comportamiento de los ganaderos riojanos en tierras de Cáceres (1720-1800". En el mismo número, Domingo Gallego tocaba el tema agrario entre 1855-1935 en La Rioja en un magistral artículo, García Armendáriz glosaba la obra de los agraristas hermanos Rodríguez Mohedano y Brumont publicaba un catálogo de tesis y tesinas sobre Historia de España leídas en la Universidad de Toulouse- Le Mirail. 
mordiales de la revista: conjugar el trabajo de investigadores de prestigio con el trabajo hecho en la casa ${ }^{34}$. El número de 1989 integraría artículos de Alonso Castroviejo, Lorenzo Cadarso, Burgos Esteban, Ibáñez Rodríguez (doctorandos del CUR) y trabajos de Pérez Escohotado y Ojeda San Miguel ${ }^{35}$. Todos los artículos de los doctorandos anuncian lo que luego serán sus tesis, que analizaremos después.

Para el equipo que se iba formando en Logroño en torno a la Historia Moderna iba a llegar el hecho más transcendental que ha producido esta ciudad en la historiografía. El Ayuntamiento encargaba, en 1987, un vasto proyecto de investigación de la historia de la ciudad, sobre un programa de trabajo bien concebido y financiado, con la colaboración de la universidad en La Rioja, mediante convenio suscrito entre Vicerrectorado de La Rioja y Ayuntamiento. Sus valedores —el alcalde Manuel Sáinz y los concejales Fernando Martínez y el malogrado Tomás Mingot- confiaron en Urbano Espinosa, rescatado para la Universidad en La Rioja, y en Gómez Urdáñez y F. Bermejo, para formar un equipo de coordinadores —al que luego se sumaría A. Sesma, de la Universidad de Zaragoza_-, que emprendiera la más amplia selección de colaboradores con cinco años por delante para trabajar antes de publicar el resultado: sencillamente "un proyecto a la americana", como lo definiría J.A. García de Cortázar. La nómina de colaboradores se acerca a los cien; en Historia Moderna, treinta y dos, varios de universidades españolas, algunos de universidades francesas, y el nutrido grupo de doctorandos e investigadores locales, a los que se suman profesores, en su mayoría del CUR, de otras áreas ${ }^{36}$.

El proyecto, además de un medio para publicar una gran obra de Historia, fue una ocasión de financiar generosamente tesis y tesinas (y pagar las colaboraciones de los profesionales) y, además, el marco en el que desarrollaron ciclos de conferencias y

34. Brocar 13, Sobre Inquisición, OLAECHEA ALBISTUR, 1987: "Francisco de Miranda y la Inquisición española: el Santo oficio, instrumento de la política de Estado" y GARMENDIA, 1987: "El Tribunal Inquisitorial de Logroño", Sobre Concejos, ALONSO CASTROVIEJO, 1987: "La crisis del municipio logroñés: los primeros procesos desamortizadores (180-1814)", HILTPOLD, 1987: "Política paternalista y orden social en la Castilla del Renacimiento", MONTEMAYOR, 1987: "La red urbana en Castilla la Nueva en los siglos XVI y XVII", BRUMONT, 1987: "La peste de 1599 en Burgos, una relación del regidor Andrés de Cañas", y PASTOR OCÓN, 1987: "Transformaciones económicas en Murillo de Río Leza, 1750-1833. Resumen de tesis de licenciatura".

35. Brocar 15, 1989. PÉREZ ESCOHOTADO, 1989: "Automedicación y dieta de Antonio Medrano, alumbrado epicúreo: sus "cédulas" gastronómicas", OJEDA SAN MIGUEL, 1989: "Notas sobre la mecanización de la pañería en Ezcaray en la primera mitad del siglo XIX", ALONSO CASTROVIEJO, 1989: La población de Logroño en los vecindarios de los siglos XVIII y XIX", IBÁÑEZ RODRÍGUEZ, 1989: "Estructura económico-social en la Rioja: la población en la segunda mitad del siglo XVII (valles de Tobía y Cárdenas)", BURGOS ESTEBAN,1989: "Las bases sociales de la élite del estamento hidalgo, el linaje hidalgo de los Barrón (Logroño, siglos XVI y XVII)" y LORENZO CADARSO, 1989: "Los malos tratos a las mujeres en Castilla en el siglo XVII".

36. El proyecto tenía tales aspiraciones de totalidad que involucró a historiadores de la literatura —Maite González de Garay, para el poeta Zárate; Julián Bravo, para el poeta Villegas; Fernández Matito, para la historia del teatro-; historiadores del arte —Ana Mendióroz, Julián Ruiz Navarro, para la escultura, J.M. Ramírez, para artes varias, etc.—; historiadores de la ciencia —Jesús Palacios, para Los Del Huyar-; historiadores de la educación, como Soubeyroux y M.H. Buisine, Rodríguez San Pedro, A. Carrasco, y otros, como J. Contreras, M.A. Cristóbal y G. Dufour, para la Inquisición. 
colaboraciones de variada índole: desde el apoyo para la microfilmación de documentos del archivo, hasta la insistencia en dotarlo de personal cualificado, lo que afortunadamente ya se ha producido. Pero, sobre todo, fue un acicate para la expansión de la investigación, porque el equipo se sabía apoyado por lo que denominábamos la última trinchera, y una experiencia que cambió hábitos tradicionales: durante seis años, todo era de todos; el ordenador central, diestramente manejado por $\mathbf{S}$. Ibáñez Rodríguez, suministró información a quien la pedía, contrastó datos - los proporcionaba elaborados, a la carta-, fichó bibliografía; realmente, aquello era un taller de historia (a veces, incluso con alojamiento incluido para visitantes de fuera) en el que se discutía el trabajo de todos, a veces con extrema virulencia (un aspecto muy hispánico que sorprendía a F. Brumont hasta que fue acostumbrándose).

En este ambiente, iniciaron su tesis Pedro Lorenzo Cadarso, Noemí Armas Lerena, Santiago Ibáñez, Gregorio Torrealba y Francisco Burgos Esteban. El grupo pertenece a la generación que en España lo ha tenido todo para formarse - medios económicos, conocimiento de idiomas, directores de investigación implicados, acceso a libros, posibilidad de viajar y conocer a los historiadores extranjeros- pero que sabía que todo se le negaría cuando completara su formación. Su radicalismo, tan beneficioso para la Historia, sólo provenía de ahí; desgraciadamente, algunos no lo supieron ver, quizás, porque sospecharon erróneamente que podían poner en peligro su seguridad académica.

Pedro Lorenzo Cadarso es el mejor ejemplo. Inició su tesis atacando directamen-

zl problema de las revueltas en los siglos XVI y XVII, convencido de que las reacciones populares no se habían logrado explicar más que con los mismos clichés que utilizaba la oligarquía cuando justificaba su represión. Su idea de una estrategia popular verdaderamente elaborada levantaba ampollas al principio, igual que el rescate del viejo concepto de la refeudalización, aplicado hace décadas por Noel Salomón y llevado a su extremo en la historiografía de los paises del Este, que él supo ponderar en su aplicación a la Castilla del XVII, haciendo de él no un concepto social de larga duración sino de estrategia política aplicada a lo que llamó cierre social de las élites urbanas nobles en el siglo XVII ${ }^{37}$. Tenía una idea del pueblo castellano que parecía salir del romanticismo (Lorenzo, 1989) —lo que provocó agrias discusiones-, y una concepción del Estado como aparato universalmente opresor, que sobrepasaba la vulgata marxista para afirmarse estrictamente en la documentación $^{38}$. Su tesis, que publicará Siglo XXI —el IER le ha negado repetidamente la publicación, a pesar de haber sido becario y de que varios investigadores de prestigio nacional la hayan recomendado repetidamente-, llenará uno de los vacíos de la

37. Su mejor plasmación está en LORENZO CADARSO, 1989: "El conflicto jornalero en Logroño (ss. XVI y XVII)", así como en varios de los capítulos incluidos en GÓMEZ URDÁÑEZ, (coord.), 1994-9: Historia de la ciudad de Logroño y en su tesis.

38. La concepción sobre el Estado Absoluto en GÓMEZ URDÁÑEZ y LORENZO CADARSO, 1993: "Las comunidades rurales frente al Estado Absoluto", ponencia que despertó una viva polémica todavía por cuestiones...terminológicas. 
historiografía española y será el desencadenante de un necesario debate sobre la crisis del XVII ${ }^{39}$.

El trabajo de Noemí Armas (1989) se centró en el estudio del funcionamiento del ayuntamiento de Logroño en los siglos XVI y XVII a base de fuentes de Simancas y de los archivos locales. Construyó un acabado estudio, con una amplia base cuantitativa sobre las finanzas municipales, que es sin duda lo mejor de su tesis de licenciatura, leida en 1989. Dos años antes el IER había publicado la tesis doctoral de José María Bañuelos (1987), defendida en la Universidad de Navarra en 1983, también sobre el Concejo, que provocó una airada crítica en la prensa local firmada por Lorenzo Cadarso - portavoz del rechazo del grupo-- a la que respondió el IER de forma corporativa y anticientífica, en el momento que marcó el punto culminante en el enfrentamiento con la institución. En realidad, eran críticas fundadas y así se demostraba en la crítica del libro aparecida en prensa (ciertamente, muy dura). El libro de Bañuelos es una descripción de los órganos municipales y de algunos hechos importantes con las únicas fuentes del archivo municipal y algunos protocolos y basado en una bibliografía muy pobre. Los problemas importantes para la historiografía - política fiscal, regimientos añales o perpetuos, control social desde el ayuntamiento, consolidación política de la élite social, etc.- , que constituían la gran preocupación de N. Armas, P.L. Lorenzo, Burgos Esteban y G. Torrealba, prácticamente no se mencionan. Lo verdaderamente irritante es que, siendo becarios del IER o disfrutando alguna ayuda para la investigación, ni se les consultaba ${ }^{40}$.

Armas Lerena seguiría dedicada a la investigación, plenamente involucrada en el proyecto de Historia de la Ciudad de Logroño - desempeñando una constante labor de organización-, en la que ha escrito magníficos trabajos sobre la administración del concejo, así como colaboraciones con S. Ibáñez y José Luis Gómez Urdáñez ${ }^{4}$.

Gregorio Torrealba trabaja un tema paralelo a N. Armas: las relaciones del concejo con el exterior a través del comercio. Hace un análisis del mercado para demostrar que existió un hiperproteccionismo del comercio del vino por parte de la oligarquía municipal hasta el punto de desviar impuestos sobre su venta, cargándolos a otros productos, incluso los de mayor necesidad. Sin embargo, el gran hallazgo de

39. Uno de los factores más interesantes para el estudio de la conflictividad social, en Lorenzo Cadarso, 1989: "El conflicto jornalero...". Del mismo autor, en Historia de la Ciudad de Logroño, varios capítulos sobre los conflictos sociales, pero, especialmente, el cap. VIII de la Edad Moderna, en el que introduce la cuestión social en las luchas por el control del agua y los pleitos por la jurisdicción de aldeas.

40. Con todo, Bañuelos colaboró en el proyecto Historia de la ciudad de Logroño, con un capítulo sobre fiestas, en colaboración con P.L. Lorenzo Cadarso, lo que demuestra la separación entre la oposición a la política cultural y el respeto al trabajo individual. Otro de los trabajos de BAÑUELOS MARTÍNEZ, 1989: "Relaciones del gobierno de Logroño con sus aldeas en el siglo XVII".

41. Un ejemplo, GÓMEZ URDÁÑEZ y ARMAS LERENA, Los señorios en La Rioja en el siglo XVIII, en prensa. Otro, ARMAS LERENA e IBÁÑEZ RODRÍGUEZ, "El final de los jesuitas en Logroño: poder económico e imbricaciones sociales", en depósito en el IER. Probablemente, el mejor artículo sobre historia eclesiástica desde LAYNA SERRANO, 1946: "Noticias documentales sobre conventos antiguos de Logroño". También, de gran interés, ARMAS LERENA, 1992: "Las ordenanzas municipales de Logroño en los siglos XVI y XVII". 
Torrealba fue el interés que mostraban siempre los regidores por mantener una buena política de abasto de pan a través del pósito - fundamental para evitar conflictos sociales (lo que no ha de entenderse como paternalismo a la manera de Hiltpold, obviamente) - que, a causa del peculiar reparto de cultivos (a veces, hasta 2/3 de viñedo), debía importar constantemente trigo del exterior. Su estudio de las rutas, que llegaban hasta Tierra de Campos, de los costos del transporte, de los mecanismos de redistribución desde Logroño - sobre todo los productos que aportan a su llegada para cargar vino los arrieros vascos- y del contrabando en la aduana de Logroño fueron básicos para entender las vías de capitalización de los mercaderes logroñeses (Torrealba, 1989 y 1992). En la actualidad ha extendido su estudio a otras localidades - Calahorra, Agreda, Haro, Santo Domingo- en un intento de explicar el funcionamiento de los pósitos.

A estas alturas de la investigación, se hacía necesario emprender el estudio de la producción. Se conocían aproximaciones y se intuían los resultados a través de las fuentes cualitativas y de algunos estudios - a destacar sobre el viñedo, el clásico de Huetz de Lemps ${ }^{42}$ - pero no había ninguna seguridad y era evidente que la importancia de algunas conclusiones - sobre todo las de Alonso Castroviejo y Lorenzo Cadarso en temas de historia social; también las de M. Lázaro y P. Gurría sobre demografía - la exigían. Santiago Ibáñez iniciaría su estudio de la producción a través de los diezmos, primero de Logroño, a causa de su participación en el equipo de Historia de la ciudad, luego, de toda La Rioja. Después, añadiría otras fuentes no eclesiásticas. En la actualidad, gracias a su esfuerzo y a la informatización de los datos, conocemos en profundidad la evolución de la producción agraria en la región, las proporciones y rentabilidad de los cultivos, etc., lo que nos acerca al conocimiento de temas muy complejos: las decisiones campesinas en cada coyuntura, la incidencia de las detracciones feudales, los tópicos límites del crecimiento, etc. Pero, además, la tesis, a punto de concluir, contiene otros asuntos - en principio, planteados como colaterales- de no menor interés, como un buen análisis de la metrología, una gran aportación al conocimiento de la propiedad eclesiástica y la diferente participación de ésta, del diezmo, de las inversiones, de las instituciones religiosas en el conjunto de sus rentas, etc. ${ }^{43}$. Todo hace pensar que el trabajo de Santiago Ibáñez será el más completo sobre diezmos de una región española.

42. HUETZ DE LEMPS, 1967: Vignes et vignobles du Nord-Ouest de l'Espagne. Como era de esperar un estudio exhaustivo sobre la región demostraría algunos errores en este magnífico libro, cuya publicación, traducido, deberían haber acometido hace años nuestras autoridades culturales.

43. Las hipótesis y los datos más importantes en IBÁÑEZ RODRÍGUEZ, 1991: La producción en La Rioja. Las fórmulas eclesiásticas de participación en el producto agrícola (siglos XVI al XVIII); el estudio completo, a punto de concluir, en su tesis doctoral, Renta campesina y renta eclesiástica en La Rioja en los siglos XVI al XVIII. Algunas colaboraciones de interés, IBÁÑEZ RODRÍGUEZ, 1994: "Hospitales del camino de Santiago en la diócesis de Calahorra y La Calzada". Sobre las diferentes estrategias del clero en la dirección de sus inversiones, hay grandes coincidencias con las conclusiones de ATIENZA, 1984: Propiedad y señorío en Aragón: el clero regular entre la expansión y la crisis, para Aragón, una investigadora, ya ganada para la Universidad de La Rioja, profesora en el campus riojano desde 1989. También es posible encontrar el 
Sobre demografía de la edad Moderna, Mercedes Lázaro y Pedro Gurría trabajaban juntos desde hacía años, bajo la dirección de J.A. Salas Ausens, de la Universidad de Zaragoza; habían publicado bastantes resultados parciales de sus investigaciones, como hemos visto, logrando un gran soporte técnico y un profundo conocimiento bibliográfico sobre el tema. Durante este periodo, colaborarían en el proyecto de Historia de Logroño y ultimarían sus tesis doctorales (la de M. Lázaro ya defendida). En 1989, publicaban un excelente estudio sobre las crisis de mortalidad en La Rioja. Pero, su trabajo más completo es el que publicarán en la Historia de la ciudad de Logroño, en varios capítulos de los dos volúmenes dedicados a la Historia Moderna: un buen ejemplo de exhaustividad y rigor científico. Desgraciadamente, su colaboración, demasiado extensa, debió ser despojada sobre todo de los aparatos técnicos; no obstante, la tesis doctoral de M. Lázaro está a punto de ser publicada al completo. Destaca, entre toda su producción, el análisis de la inmigración en la ciudad de Logroño en el siglo XVIII, en el que exponen resultados cuantitativos verdaderamente sorprendentes, fruto de la existencia de una fuente, única en España, como son los libros de parroquianos. Estos libros, que existen en la ciudad al ser libre la adscripción de los vecinos a las diferentes parroquias, contienen los registros de los inmigrantes. De ahí que, al análisis de las variables clásicas de la demografía, se una en la Historia de Logroño el menos frecuente en época preestadística de los movimientos migratorios, con lo que los resultados totales son espectaculares ${ }^{44}$.

El balance del periodo es, pues, muy positivo. Se han leido o están en curso varias tesis de licenciatura y tesis doctorales; se va a coronar con éxito el gran proyecto de Historia de Logroño - sobre el que aún habremos de volver luego-; se ha relanzado la revista Cuadernos, Brocar y se ha ampliado el número de publicaciones. Pero, además, por primera vez, salvo excepciones, la historia de La Rioja ha trascendido al exterior, no sólo porque los investigadores hayan dado a conocer fuera su trabajo, sino porque los proyectos y los intercambios han logrado atraer a investigadores de otra universidades hacia temas regionales. Es el caso de Angeles Cristóbal, que ya trabajaba bajo la dirección de Jaime Contreras sobre la Inquisición en La Rioja antes de ser conocida por los investigadores riojanos (Cristóbal, 1986): su interés por el Tribunal de Logroño se debía, no tanto —es obvio - al interés por la región como a la atracción que para el equipo de Contreras ejercía el vacío historiográfico. No obstante, luego, colaboraría en varios proyectos, especialmente en la Historia de la ciu-

fruto de la colaboración de S. Ibáñez con Brumont en la tesis de éste último, BRUMONT, 1993: Paysans de Vieille-Castille aux XVIe et XVII siècles y en la colaboración de ambos en la Historia de la Ciudad de Logroño. Igualmente, sus aportaciones han llegado a la tesis de Marc Martí, 1994: Ville et campagne en l'Espagne des lumieres.

44. El análisis de la inmigración en lo referente a las provincias vascas fue dado a conocer por los autores en LÁZARO RUIZ, GURRÍA GARCÍA y ORTEGA BERRUGUETE, 1988: "La emigración vasca a La Rioja durante la Edad Moderna. Los libros de parroquianos de la ciudad de Logroño". La inmigración en general, en LÁZARO RUIZ, 1994: La población de la ciudad de Logroño durante el Antiguo Régimen (15001833). También, resumido, en GÓMEZ URDÁÑEZ (coord.), 1995: Historia de la ciudad de Logroño. 
dad de Logroño, en la que destaca su extenso trabajo sobre el Tribunal en los siglos XVI y XVII. (Cristóbal, 1987, 1994 y 1995) El mismo proyecto atrajo a otros investigadores; algunos ya habían trabajado sobre temas de historia regional, como Brumont (CNRS) ${ }^{45}$, Dufour (Aix-en-Provence ${ }^{46}$, Rodríguez-San Pedro (Salamanca); otros, iniciarían su colaboración motivados por el planteamiento del trabajo, como Contreras (Alcalá), Soubeyroux (Saint Etienne), Carrasco (Alcalá), Melón Jiménez (Extremadura), Carretero (Complutense), etc. En cualquier caso, su colaboración ha sido fundamental, tanto para el proyecto como para la difusión de algunos temas de interés hitoriográfico general, sin olvidar la ayuda humana y el estímulo recibidos por el grupo local, verdaderamente impagable ${ }^{47}$.

\section{AÑOS DE ESPERANZA, 1991-1994}

La creación de la Universidad de La Rioja en 1992 es, indiscutiblemente, el acontecimiento histórico más importante ocurrido en esta región desde la concesión de su autonomía; como fenómeno cultural, es un logro sin precedentes, difícil de justificar-para algunos todavía más inexplicable que la autonomía—; como fenómeno social, un factor de cambio y modernización; como praxis política, una oportunidad de superar los obstáculos administrativos a los que había conducido la estructura anterior y — de nuevo, como en la autonomía - una necesidad en el nuevo mapa español de universidades provinciales proyectado por el gobierno socialista, difícil de completar de nuevo en esta parte de la frontera castellana.

Es posible que, en un principio, el proyecto de universidad fuera contemplado sólo como una descentralización; así se desprende de la política presupuestaria ini-

45. Francis Brumont fue el ponente de Historia Moderna en el II Coloquio con un artículo de síntesis, que ya hemos valorado. Su constante colaboración con nosotros, sus contribuciones a nuestros debates, pero sobre todo, su constante trabajo en Logroño desde 1986, está presente en una amplia variedad de artículos publicados en revistas francesas. Véase la bibliografía citada de este autor.

46. La colaboración de Dufour se debe al conocimiento de su trabajo en el Archivo de la Catedral de Calahorra y a que es, sin duda, uno de los mejores estudiosos de Llorente y de la Inquisición en su época final. Prueba de ello son algunas de las publicaciones que se citan al final y su excelente colaboración en la Historia de la Ciudad de Logroño.

47. Gracias a esta colaboración, algunos investigadores han podido publicar temas regionales en medios muy importantes; ya hemos citado el artículo de LÁZARO y GURRÍA en Annales de Demographie Historique, o los de Lorenzo Cadarso en la Revista de Historia Social y Alonso Castroviejo, en Agricultura y Sociedad, por ejemplo. También han asistido a congresos internacionales — Santiago Ibáñez, Jornadas Internacionales de Flaran —, han realizado intercambios y estancias en el extranjero —Santiago Ibáñez, Toulouse; Gómez Urdáñez, Montpellier - y han visto utilizados sus trabajos por investigadores nacionales y extranjeros, por ejemplo, los de Alonso Castroviejo, Santiago Ibáñez y G. Torrealba en la tesis de Marc Martí. Por último, se ha involucrado en el equipo a investigadores que comienzan, de variada procedencia, como es el caso de M.H. Buisine (U. de Saint Etienne), que empieza su tesis doctoral sobre la educación en La Rioja en los siglos XVIII y XIX, dirigida por J. Soubeyroux. Por el contrario, algunos miembros del equipo han ido abandonándonos en beneficio de otras universidades; así, P.L. Lorenzo, profesor en la Ỷniversidad de Extremadura, R. Moreno Fernández, en la de Huelva, o F. Burgos Esteban, en la Complutense. Saben que aquí son imprescindibles, pero allí está su futuro. 
cial, una simple prolongación de lo que el distrito riojano obtenía de la Universidad de Zaragoza, tan escaso que invalidaba de antemano las proclamas eufóricas sobre la universidad de calidad que se decía se iba a construir. La grave contradicción fue el principal elemento al que se adhirió la oposición política regional para contrarrestar el triunfo gubernamental que suponía la creación de la universidad, hasta el punto de lograr desencadenar una fuerte crisis social, que desembocó en el desgobierno y la paralización de la universidad. Al calor del fracaso, crecieron los irredentismos de quienes pensaron que la universidad sería una prolongación de la estructura del campus anterior, y que se conservarían las viejas prerrogativas. Algunas, como hemos visto, derivaban del IER, controlado por el grupo que, para su sorpresa, sería desplazado del poder en la universidad, lo que provocó el cierre numantino de la vieja guardia de la institución y su oposición a colaborar en el desarrollo de la universidad de los otros, a la que veían como un competidor. A un artículo en la prensa, firmado por el que suscribe, en el que se solicitaba un debate en la institución sobre su papel en la nueva situación, se contestó de nuevo corporativamente y con un desprecio extremo. No pasaba nada porque hubiera universidad en La Rioja: el IER seguiría contando con un presupuesto de más de ochenta millones de pesetas, mientras - y parecía no importar al grupo IER (no olvidemos que estaba formado por profesores universitarios) - el gobierno regional no ponía una peseta en la universidad; como dirían algunos dirigentes, la universidad debía acudir al gobierno de Madrid, que es el que la había traído. Desgraciadamente, desde el IER se aplaudía este grotesco comportamiento y se maniobraba para hacer fracasar el proyecto inicial sin otra alternativa que la vuelta al poder.

Sólo el proceso abierto a fines del 93, que culmina con la normalización democrática de la universidad y la ruina moral del grupo IER, logrará producir un cambio profundo, tanto en el gobierno regional como en el seno de la universidad; el resultado no podía ser más que el esperado: la universidad empieza a desarrollar su labor directora de la investigación, apoyada ya institucionalmente y por la iniciativa privada, mientras el IER por inercia va ocupando su papel - muy necesario, por otra parte- - de difusor y animador de la cultura regional. Lograr su colaboración con la universidad es el objetivo de la siguiente etapa.

En lo relativo a la Historia, la Universidad ha provocado una frustración inicial: la desaparición de la carrera de Geografía e Historia en el campus riojano y la necesaria adaptación de los historiadores a la nueva titulación de Humanidades, en cuyos planes, la posibilidades de especialización por áreas disminuye. No obstante, el impacto negativo de la innovación será probablemente relativo; primero, porque no es posible un tercer ciclo sin especializar al doctorando antes de que las fuentes lo acaben haciendo; segundo, porque el corsé de las áreas cronológicas tradicionales se está quedando muy estrecho y, a menudo, constituye un obstáculo para el desarrollo de campos muy novedosos y problemas historiográficos importantes en los que la historiografía española no prospera precisamente a causa de la dificultad de ampliar 
el taller del historiador ${ }^{48}$. Superar la incomunicación de áreas y ampliar los recursos intelectuales del historiador es el reto de los nuevos planes, que hay que asumir desde el horizonte de la creación de equipos interdisciplinares y con la confianza del desarrollo de la Historia como ciencia social entre ciencias sociales. En otro caso, habría que pensar en viajar fuera del limes barbarorum del individualismo funcionaril.

La Historia Moderna ha continuado su desarrollo durante esta etapa sin excesivos cambios sobre la anterior. Ha crecido en el número de profesores con la incorporación de Angela Atienza, desde 1989, y ve culminados con éxito algunos proyectos, especialmente el de la Historia de la Ciudad de Logroño, cuyos volúmenes III y IV, dedicados Moderna, van a ser presentados antes de que estas lineas vean la luz.

Atienza produce durante esta etapa un gran caudal de trabajo sobre temática aragonesa (Atienza, 1993 y 1994) y aporta nuevas ideas y una excelente preparación teórica, con lo que se abren nuevas posibilidades en la formación de modernistas y en la ampliación de los debates científicos y los temas a investigar. Por otra parte, M.A. Cristóbal acaba de publicar de su tesis sobre el Tribunal de Logroño (Cristóbal, 1995) y Santiago Ibáñez defenderá la suya, sobre renta eclesiástica y renta campesina en La Rioja, en mayo. Francis Brumont ha publicado su trabajo sobre los campesinos castellanos (Brumont, 1993), en el que recoge algunas aportaciones de los modernistas riojanos, mientras aparecen publicaciones en varios medios, por ejemplo, un artículo de S. Ibáñez sobre las rentas del clero en La Rioja, en las actas de las Jornadas Internacionales de Flaran (Ibáñez, 1991), un librito, actualmente en prensa, sobre los señoríos riojanos en el siglo XVIII, a cargo de Armas Lerena y Gómez Urdáñez, o una obra sobre el monte público en La Rioja en los siglos XVIII y XIX de R. Moreno, que acaba de aparecer (Moreno, 1994).

Tanto por causas biológicas como por el triunfo de la profesionalidad, la nueva etapa se salda con la práctica desaparición de la escena de los eruditos locales. Algunos vuelven a publicar, pero ya fuera de los medios institucionales. Es el caso de Jerónimo Jiménez, que da a la imprenta un librito sin pie, ni ISBN, ni depósito legal, sobre "La plaza de toros de Logroño en su setenta y cinco aniversario", probablemente en 1992, y una "Guía de Logroño", en 1994. Aunque todavía el IER publicaría en 1992 una historia de la parroquia de La Redonda, poco justificada en la nueva situación historiográfica y con escasas aportaciones sobre la bibliografía que utiliza $^{49}$. Más interés tiene el trabajo de M.A. Moreno Ramírez de Arellano, un inten-

48. Un ejemplo de las posibilidades e innovación lo constituye la tesis doctoral en curso de Ana Mendióroz sobre las políticas sobre urbanismo en La Rioja Alta. Procedente de la Historia del Arte, intenta reconstruir las ideas y las políticas urbanísticas en los siglos XVI al XIX, pero tropieza con factores históricos, como la diferencia de normativas en el señorío y el realengo, la influencia del tipo de propiedad, la organización de caseríos en función del tipo de cultivo, por lo que ha de utilizar diferentes técnicas, las propias de la historia económica y las que proceden del mundo del arte y del tan escasamente estudiado de la arquitectura popular.

49. SÁINZ RIPA 1992: Santa María de La Redonda, de iglesia parroquial a iglesia concatedral, siglos XII al XX. Sorprenden en la selección de la bibliografía citada algunas ausencias, sobre todo en temas de diezmos y propiedades de esta parroquia, muy trabajados por S, Ibáñez. 
to de reconstrucción del señorío de los Ramírez e Arellano, aunque es muy desigual, por efecto de planteamiento; lo más interesante, algunas fuentes extrarregionales bien elegidas (Moreno Ramírez, 1992).

La nueva etapa que se abre estará marcada por lo que la Universidad sea capaz de lograr. Nace en un momento difícil y tiene contra sí poderosos factores, entre los que no es el menor la escasa población estudiantil que puede atraer a los estudios de Historia; con todo, el futuro es de la universidades pequeñas en las que puedan consolidarse equipos muy integrados trabajando en grandes proyectos con fuerte respaldo exterior. En La Rioja, habrá que abrir un gran debate sobre planes de futuro en la investigación histórica; sin duda, la historiografía regional, aunque tenga aún algunas lagunas, ha sido reforzada durante los últimos años y, posiblemente, no pueda continuar siendo el único objetivo, como, por pura necesidad, lo era hasta hoy. El reto de los investigadores riojanos consistirá en proyectar problemas historiográficos de interés general y construir grupos heterogéneos, tanto por especialización como por procedencia geográfica, que viertan sus conclusiones en el marco de la historia europea. Si al cerrar el II Coloquio de Historia de La Rioja era evidente que no habría otro, ahora, al terminar estas páginas, podemos prever - y es lo que deseamos-que cuando haya que hacer inventario dentro de otros veinte años, el trabajo de los investigadores haya superado los condicionantes políticos y sociales de esta etapa: lo que supone, sin duda, traspasar el marco territorial de la Comunidad Autónoma de La Rioja y acogerse al espíritu universalista que hay que devolver reforzado a la universidad española.

Probablemente, entonces, más viejos y menos luchadores, veremos el resultado de nuestra labor y con nostalgia recordaremos el entusiasmo que pusimos en hacer de la Historia un proyecto de progreso social, empeñados en la devolución de la memoria a quienes creíamos que nos habían confiado su rescate... aunque, también entonces, constataremos que, ni antes ni después, puede hacerse creíble nuestro trabajo de clase ociosa bien remunerada. 
JOSÉ LUIS GÓMEZ URDÁÑEZ

\section{BIBLIOGRAFIA ${ }^{50}$}

ABAD LEON, F. 1975

Arnedo y su comarca durante la guerra de la Independencia, Estudio documental, Logroño. 151.

ABAD LEON, F. 1975

"Geografía Mariana de La Rioja": Berceo 89, 191-216.

ABAD LEON, F. 1978

Radiografía histórica de Logroño a la luz del catastro del Marqués de la Ensenada, Logroño. 577.

ABAD LEON, F. 1984

"Ambiente religioso creado en La Rioja a raíz del cólera morbo de 1885": I Coloquio sobre Historia de La Rioja, 317-330, Logroño.

ABAD LEON, F. 1985

El marqués de la Ensenada, su vida y su obra, Madrid.

ALONSO CASTROVIEJO, J.J. 1986

La transición en Logroño, 1766-1833, tesis de licenciatura inédita, Universidad de Zaragoza.

ALONSO CASTROVIEJO, J.J. 1987

"La crisis del municipio logroñés: los primeros procesos desamortizadores (1801 1814)": Brocar 13, 95-128.

ALONSO CASTROVIEJO, J.J. 1989

"La población de Logroño en los vecindarios de los siglos XVIII y XIX,": Brocar 15, 45-61.

ALONSO CASTROVIEJO, J.J. 1990

"Estructura socioprofesional en Logroño, 1751-1857": Berceo 118-119, 207-217.

ALONSO CASTROVIEJO, J.J. 1990

Logroño, 1751: Las respuestas generales del Catastro de Ensenada, Madrid.

ALONSO CASTROVIEJO, J.J. 1991

"La evolución del viñedo riojano durante los siglos XVII y XVIII": Agricultura y Sociedad 59, 41-72.

50. La revista del Colegio Universitario es Cuadernos de Investigación, que desde el número 12 (1986), pasó a denominarse Brocar. En los libros publicados por el IER, se cita la correspondiente colección, especialmente Biblioteca de Autores Riojanos, B.A.R. y la patrocinada por el Ayuntamiento de Logroño, Colección Logroño. 
ALONSO CASTROVIEJO, J.J. 1992

Problemática agraria, solución burguesa, Logroño, 1750-1833, (prólogo de Gómez Urdáñez, J.L.), Logroño. Col. Logroño, 254 pp.

ALONSO CASTROVIEJO, J.J. 1995

"Los nombres del Liberalismo riojano: de Domingo Santacruz a Baldomero Espartero": Historia de la ciudad de Logroño, Gómez Urdáñez, J.J. (coord.), Historia de la ciudad de Logroño, vol. IV, 313-316, Logroño.

ANSÓN CALVO, M.C. 1977

"Sociología del bautismo en el siglo XVII": Cuadernos de Investigación III, 69-89.

ARMAS LERENA, N. e Ibáñez Rodríguez, S. 1994

"El final de los jesuitas en Logroño: poder económico e imbricaciones sociales", en depósito en el IER.

ARMAS LERENA, N. 1992

"Las ordenanzas municipales de Logroño en los siglos XVI y XVII: fundamento y regulación de la vida cotidiana", Actas del Congreso "Borja y la raya occidental de Aragón", 211-220, Zaragoza.

ARMAS LERENA, N. 1989

La administración del concejo logroñés en los siglos XVI y XVII, Tesis de licenciatura inédita, Universidad de Zaragoza.

ARMILLAS VICENTE, J.A. 1977

"El nacimiento de una gran nación. Contribución española a la independencia de los Estados Unidos de América del Norte": Cuadernos de Investigación III, 91-98.

ATIENZA LÓPEZ, A., 1994

Propiedad y señorio en Aragón: el clero regular entre la expansión y la crisis, Zaragoza. Institución Fernando el Católico.

ATIENZA LÓPEZ, A., 1993

"La propiedad de la tierra en España en la edad Moderna: propuestas para un debate": Señorío y feudalismo en la Península Ibérica (ss. XII-XIX), Sarasa, E y Serrano E. (edits.), vol. I, 197-222, Zaragoza.

BAIGORRI JALÓN, J. 1976

"Alberite en el siglo XVIII (Análisis del Catastro de Ensenada)": Berceo 91, 207226.

BAÑUELOS MARTÍNEZ, J.M. 1989

"Relaciones del gobierno de Logroño con sus aldeas en el siglo XVII": Berceo 116117, 97-109.

BAÑUELOS MARTÍNEZ, J.Ma 1989

El Concejo logroñés en los siglos de Oro, Logroño. Colección Logroño, 283. 
JOSÉ LUIS GÓMEZ URDÁÑEZ

BERMEJO MARTÍN, F. 1984

La Segunda República en La Rioja, Elecciones y Contexto político, Logroño. B.A.R., 497.

BRUMONT, F. 1978

"L'evolution de la population rurale durant le régne de Philipe II, l'exemple du nordouest de la Vieille Castille": Melanges de la Casa de Velázquez XIV, 249-268.

BRUMONT, F. 1984

"L'exploitation paysanne en Vieille Castille à la fin du XVIe siècle": Congreso de Historia Rural, Madrid.

BRUMONT, F. 1984

Campo y campesinos de Castilla la Vieja en tiempo de Felipe II, Madrid.

BRUMONT, F. 1986

"La Rioja en el siglo XVI": Segundo Coloquio sobre Historia de La Rioja, vol. II, 11-70, Logroño.

BRUMONT, F. 1987

"La peste de 1599 en Burgos, una relación del regidor Andrés de Cañas": Brocar 13, 155-166.

BRUMONT, F. 1991

"Transformations du vignoble du Vieille Castille au XVIIe siècle": XI journées Internationales d'Histoire, Flaran.

BRUMONT, F. 1992

"Les restrictions à l'elevage en Vieille Castille au XVIe siècle": Melanges de la Casa de Velázquez XXVIII-2.

BRUMONT, F. 1993

"Le mariage, passeport pour l'ascension sociale: à Logroño au XVI siècle": Pouvoirs et soiecté dans l'Espagne moderne. Hommage a Bartolome Bennassar, 89-100, Toulouse.

BRUMONT, F. 1993

Paysans de Vieille-Castille aux XVIe et XVII siècles. Madrid.

BURGOS ESTEBAN, F.M. 1989

Las bases sociales de la élite del estamento hidalgo, el linaje hidalgo de los Barrón (Logroño, siglos XVI y XVII)": Brocar 15, 91-117.

CANTERA MONTENEGRO, E. 1982

"Inquisición de Logroño: Sambenitos del siglo XVI": Berceo 103, 51-68. 
CANTERA MONTENEGRO, M. 1985

"Pleitos por términos del concejo de Logroño, 1475-1495": Berceo 108-109, 71-80.

CARASA SOTO, P. 1984

"Crisis y transformación de la beneficencia del Antiguo Régimen. Aproximación al sistema hospitalario de La Rioja entre 1750 y 1907": I Coloquio sobre Historia de La Rioja, 7-26, Logroño.

CORONA BARATECH, C. 1975

"Sobre el tránsito del absolutismo al liberalismo": Cuadernos de Investigación I-2, 63-82.

CORONA BARATECH, C. 1977

"Los sucesos ocurridos desde marzo a mayo de 1766 en Tobarra, Oviedo, Totana, Quesada y Lietor": Cuadernos de Investigación III, 99-120.

CRISTOBAL MARTÍN, A. 1986

"La Inquisición de Logroño: mentalidad popular en el agro riojano": Segundo Coloquio sobre Historia de La Rioja, vol. II, 83-90, Logroño.

CRISTÓBAL MARTÍN, A. 1987

"La visita de Distrito, medio de radicación del sistema Inquisitorial de control social, El Santo Oficio de Logroño (1538-1613)": Brocar 13, 65-96.

CRISTÓBAL MARTÍN, A. 1995

Confianza, fidelidad y obediencia. Servidores inquisitoriales y dependencias personales en la ciudad de Logroño, siglo XVII. Logroño, Colección Logroño.

DE BUNES IBARRA, M.A. 1984

"Incidencias de la Real Fábrica de Paños de Santa Bárbara y San Carlos y la explotación minera en la demografía de Ezcaray en la segunda mitad del XVIII": I Coloquio sobre Historia de La Rioja, 219-228, Logroño.

DUFOUR, G. 1982

Juan Antonio Llorente en France (1813-1822), Contribution a l'etude du liberalisme chrétien en France et en Espagne au début du XIX siècle, Genève. Droz Editeur, 375.

DUFOUR, G. 1983

"Juan Antonio Llorente: de servidor a crítico de la Inquisición": Historia 16, 83, 1320.

DUFOUR, G., 1988

"Las ideas político-religiosas de Juan Antonio Llorente": Cuadernos de Historia Contemporánea de la Universidad Complutense 10, 11-22. 


\section{JOSÉ LUIS GÓMEZ URDÁÑEZ}

DUFOUR, G. 1995

"La Inquisición: algo más que un símbolo al final del Antiguo Régimen": Historia de la ciudad de Logroño, coord. Gómez Urdáñez, J.L. vol. IV, 281-318, Logroño.

FERNÁNDEZ CLEMENTE, E. 1986

"Sobre la crisis de la ganadería española en la segunda mitad del XVIII": Brocar 12, 89-101.

FERNÁNDEZ DE BOBADILLA, F. 1972

Apuntes para la Historia de Arnedo, Arnedo.

FERNÁNDEZ MARCO, J.I. 1976

La muy noble y muy leal Villa de Briones. Estudio Biográfico, Logroño. 366.

FERRER BENIMELI, J.A. 1975

"Voltaire y la Masonería": Cuadernos de Investigación I-1, 65-89..

FERRER BENIMELI, J.A. 1978

"La Masonería bonapartista en Aragón": Cuadernos de Investigación IV-2, 91-108.

FONTANA, J. 1982

Historia, análisis del pasado, proyecto social, Barcelona.

FRANCO ALIAGA, T. 1979

"La población de la ciudad de Logroño desde el siglo XI al XVI": Cuadernos de Investigación $\mathrm{V}-1,91-104$.

GARCÍA DE CORTÁZAR, J.A.

"Introducción al estudio de la sociedad altorriojana en los siglos X al XIV": Berceo. $88,3-29$.

GARCÍA PRADO, J. 1951

Historia de la Cultura, cuarto curso, Logroño, Gráficas Ochoa.

GARCÍA TURZA, C. 1975

Matute y su léxico, 1. Labores agrícolas, Logroño. 178.

GARCÍA, M. y GONZÁLEZ BLANCO, A. 1975

"Un documento papal del siglo XVII dirigido a la aldea de Navalsaz": Berceo 89, $157-166$.

GARMENDIA, B.Z. 1987

"El Tribunal Inquisitorial de Logroño": Brocar 13, 57-63.

GÓMEZ URDÁÑEZ, J.L. 1982

Marginación social y beneficencia en Aragón en el siglo XVIII, tesis doctoral inédita, Universidad de Zaragoza. Hay resumen con el mismo título en Tesis doctorales, Zaragoza, 1993. 
VEINTE AÑOS DE HISTORIA MODERNA EN LA RIOJA

GÓMEZ URDÁÑEZ, J.L. 1986a

"Estado actual de la Historia Moderna en La Rioja": Monográfico dedicado a La Rioja, Andalán, Zaragoza.

GÓMEZ URDÁÑEZ, J.L. 1986b

"Reacciones populares en Logroño durante la guerra de Sucesión": Segundo Coloquio sobre Historia de la Rioja vol. II, 181-192.

GÓMEZ URDÁÑEZ, J.L. 1986c

"Subsistencia y descapitalización en el Camero Viejo al final del Antiguo Régimen": Brocar 12, 103-139.

GÓMEZ URDÁÑEZ, J.L. y LORENZO CADARSO, P.L. 1993

"Las comunidades rurales frente al Estado Absoluto": Melanges de la Casa de Velázquez XXIX-2, 79-92.

GÓMEZ URDÁÑEZ, J.L. 1994

"Aviso para caminantes en el Logroño del siglo de Oro": Historia de la Ciudad de Logroño, vol. III, 13-24, Logroño.

GÓMEZ URDÁÑEZ, J.L. (cord,). 1994-95

Historia de la Ciudad de Logroño, Edad Moderna, Logroño, vols. III y IV. Logroño.

GÓMEZ URDÁÑEZ, J.L. y Armas Lerena, N. 1995.

Los señorios en La Rioja en el siglo XVIII, en prensa.

GONZÁLEZ BLANCO, A. 1984

"El concepto de "provincia" en el Compendio Historial de la Provincia de La Rioja del P. Matheo de Anguiano": I Coloquio sobre Historia de La Rioja, 275-286, Logroño.

GONZÁLEZ ENCISO, A. 1984

"La industria dispersa en Cameros, 1700-1840": I Coloquio sobre Historia de La Rioja, 39-58, Logroño

GURRÍA GARCÍA, P. 1986

"La estructura familiar en La Rioja, Cellorigo, 1747-1833": Segundo Coloquio sobre Historia de La Rioja vol. II, 199-212, Logroño.

GURRÍA GARCÍA, P. 1984

"Observaciones sobre la estructura familiar camerana en la época Moderna": I Coloquio sobre Historia de La Rioja, 57-70, Logroño.

HERNÁNDEZ GARCÍA. A. 1984

La represión en La Rioja durante la guerra civil, Logroño.

HERNÁNDEZ LÁZARO, J.F. 1975

"El Solar de Tejada: una incidencia en Clavijo": Berceo 89, 217-226. 
HILTPOLD, P., 1987

"Política paternalista y orden social en la Castilla del Renacimiento": Brocar, 13, $129-140$

HUETZ DE LEMPS, A. 1967

Vignes et vignobles du Nord-Ouest de l'Espagne, Bordeaux.

IBÁÑEZ RODRÍGUEZ, S. 1989

"Estructura económico-social en la Rioja: la población en la segunda mitad del siglo XVII (valles de Tobía y Cárdenas)": Brocar, 15, 63-89.

IBÁÑEZ RODRÍGUEZ, S. 1991

La producción en La Rioja. Las fórmulas eclesiásticas de participación en el producto agrícola (siglos XVI al XVIII), tesis de licenciatura inédita, Zaragoza; el estudio completo, a punto de concluir, en su tesis doctoral, Renta campesina y renta eclesiástica en La Rioja en los siglos XVI al XVIII.

IBÁÑEZ RODRÍGUEZ, S. 1991

"Proprieté et rentes du clergé dans La Rioja au XVI et XVIe siècles": Jornadas Internacionales de Flaran, en prensa, corregidas pruebas.

IBÁÑEZ RODRÍGUEZ, S. 1994

"Hospitales del camino de Santiago en la diócesis de Calahorra y La Calzada": IV Semana de Estudios Medievales, 309-321, Logroño.

ITURRIOZ MAGAÑA, A. 1987

Estudio del subsidio y excusado (1561-1808). Contribuciones económicas de la Diócesis de Calahorra y La Calzada a la Real Hacienda, Logroño. 406 pp.

LAYNA SERRANO. 1946

"Noticias documentales sobre conventos antiguos de Logroño": Berceo, 1, 9-58.

LÁZARO RUIZ y GURRIA GARCÍA, P. 1982

"La crisis de mortalidad de 1631 en La Rioja": Cuadernos de Investigación VIII, 53100.

LÁZARO RUIZ, M. GURRIA GARCÍA, P. et BRUMONT, F. 1989

"La population de La Rioja au XVIe siècle": Annales de Démographie historique 1988, Paris, 221-241.

LÁZARO RUIZ, M. 1984

"Torre en Cameros: la movilidad de población en un núcleo de montaña durante los siglos XVII y XVIII": I Coloquio sobre Historia de La Rioja., 71-90, Logroño.

LÁZARO RUIZ, M. y GURRÍA GARCÍA, P. 1989

Las crisis de mortalidad en La Rioja (siglos XVI y XVII), Logroño. B.A.R.,196 pp. 
LÁZARO RUIZ, M. y MARTÍN MARTÍN, R. 1984

"Demografía histórica: Metodología para ordenadores aplicada al sistema de reconstrucción de familias en los Cameros durante los siglos XVII y XVIII": I Coloquio sobre Historia de La Rioja, 91-112, Logroño.

LÁZARO RUIZ, M., GURRÍA GARCÍA P. y ORTEGA BERRUGUETe, A. 1988 "La emigración vasca a La Rioja durante la Edad Moderna. Los libros de parroquianos de la ciudad de Logroño": Ernaroa, 5, 5-50.

LÁZARO RUIZ, M. 1986

"Paisaje agrario y propiedad de la tierra en la villa de Albelda durante el Antiguo Régimen": Segundo Coloquio sobre Historia de La Rioja vol. II, 139-168, Logroño.

LAZARO RUIZ, M. 1994

La población de la ciudad de Logroño durante el Antiguo Régimen (1500-1833), Logroño. Colección Logroño.

LÓPEZ DE SILANES, C. y SAÍNZ RIPA, E. 1985, 1989, 1991 y 1992

Colección diplomática calceatense, Logroño. 4 vols.

LORENZO CADARSO, P. 1992

La conflictividad popular en Castilla (ss. XVI y XVII), 2 vols., tesis doctoral, Universidad de Zaragoza, en prensa en Editorial Siglo XXI.

LORENZO CADARSO, P.L. 1989

"El conflicto jornalero en Logroño (ss. XVI y XVII)": Berceo 116-117, 81-96.

LORENZO CADARSO, P.L. 1989

"Los malos tratos a las mujeres en Castilla en el siglo XVII": Brocar 15, 119-136.

LORENZO CADARSO, P.L. 1989

"Luchas políticas y refeudalización en Logroño en los siglos XVI y XVII": Revista de Historia Social 5, 3-23.

MAISO GONZÁLEZ, J. 1975

"La coyuntura económica de Aragón a mitad del siglo XVII y el motín contra los valones": Cuadernos de Investigación I-1, 91-108.

MAISO GONZÁLEZ, J. 1975

"Baltasar Carlos y Zaragoza": Cuadernos de Investigación I-2, 95-100.

MAISO GONZÁLEZ, J. y SALAS AUSENS, J.A. 1976

"La población de Huércanos (provincia de Logroño) según los registros parroquiales (1550-1700)": Cuadernos de Investigación II, 51-81.

MANZANARES, A. 1982

El marqués de la Ensenada, estadista universal, Logroño. Roldana Editorial. 
JOSÉ LUIS GÓMEZ URDÁÑEZ

MARCOS POUS, A. 1979

Trabajos arqueológicos en la Libia de los Berones, Logroño. 278 pp.

MARTI, M. 1994

Ville et campagne en l'Espagne des lumieres, tesis doctoral, Universidad de Saint Etienne.

MELÓN JIMÉNEZ, M.A. 1986

"De Cameros a Extremadura. Historia y comportamiento de los ganaderos riojanos en tierras de Cáceres (1720-1800)": Brocar 12, 141-158.

MONTEMAYOR, J. 1987

"La red urbana en Castilla la Nueva en los siglos XVI y XVII": Brocar 13, 141-153.

MORENO FERNÁNDEZ, J.R. 1994

El monte público en La Rioja en los siglos XVIII y XIX, (prólogo de Gómez Urdáñez, J.L.), Logroño. Consejería de Medio Ambiente.

MORENO RAMÍREZ DE ARELLANO, M.A. 1992

Señorío de Cameros y Condado de Aguilar: Cuatro siglos de régimen señorial en La Rioja (1366-1733), Logroño. B.A.R., 235 pp.

MOYA VALGAÑóN, J. G. y Ruiz, J.J. 1975

Enciso Monumental, Logroño. 93 pp.

MOYA VALGAÑóN, J.G. 1980

Arquitectura religiosa del siglo XVI en La Rioja Alta, Logroño. 2 vols., 126 y 220 pp.

OJEDA SAN MIGUEL, R. 1986

"La Real Sociedad riojana de Amigos del País y la villa de Miranda de Ebro": Segundo Coloquio sobre Historia de La Rioja vol. II, 213-224, Logroño.

OJEDA SAN MIGUEL, R. 1989

"Notas sobre la mecanización de la pañería de Ezcaray en la primera mitad del siglo XIX": Brocar 15, 31-43.

OLAECHEA ALBISTUR, R. 1976

"El anticolegialismo del gobierno de Carlos III": Cuadernos de Investigación II-2, 53-90.

OLAECHEA ALBISTUR, R. 1978

"Resonancias del motín contra Esquilache en Córdoba": Cuadernos de Investigación IV-1, 75-124.

OLAECHEA ALBISTUR, R. 1987

"Francisco de Miranda y la Inquisición española: el Santo Oficio, instrumento de la política de Estado": Brocar 13, 29-56. 
OLAECHEA ALBISTUR, R. 1985

Viajeros españoles del XVIII en los balnearios del Alto Pirineo Francés, Logroño. CUR, 80 pp.

OLLERO DE LA TORRE, J.L. 1981

Un riojano en las cortes de Cádiz: el obispo de Calahorra don Francisco Mateo Aguiriano y Gómez, Logroño. B.A.R., 192 pp.

PALACIOS SÁNCHEZ, J.M. 1975

"La vida social y económica de la ciudad de Logroño en los siglos XVI y XVII": Berceo 89, 227-269.

PASTOR OCON, J.L. 1987.

"Transformaciones económicas en Murillo de Río Leza, 1750-1833. Resumen de tesis de licenciatura": Brocar 13, 167-176.

PASTOR OCÓN, J.L. 1989

Transformaciones económicas en Murillo de Río Leza (La Rioja), 1750-1833, Logroño.

PEÑA, J., O.A.R., y RODRIGO IÑIGUEZ. 1975

"Abad de Silos ¿Fue antes monje y prior de San Millán?": Berceo 89, 147-156.

PÉREZ ESCOHOTADO, J. 1989

"Automedicación y dieta de Antonio Medrano, alumbrado epicúreo: sus "cédulas" gastronómicas": Brocar, 15, 7-27.

RAMÍREZ COMPES, J.A. 1982

"Conflictos fronterizos en los valles franceses y aragoneses del Pirineo en el siglo XVIII": Cuadernos de Investigación VIII, 101-114.

RAMÍREZ MARTÍNEZ, J.M. y SÁINZ RIPA, E. 1977

El Miguel Angel de La Redonda, Logroño. 218 pp.

RODRÍGUEZ SAN PEDRO BEZARES, L.E. 1986

"Universitarios riojanos en la Salamanca del Siglo de Oro, 1600-1630": Segundo Coloquio sobre Historia de La Rioja vol. II, 71-82, Logroño.

RUIZ DE GALARRETA, J.M. 1975.

"La heráldica de Lumbreras de Cameros, datos para la Historia": Berceo 89, 135-146.

SÁENZ TERREROS, M.C. 1986

El Hospital de peregrinos y la cofradía de Santo Domingo de la Calzada, desde su fundación hasta la crisis del Antiguo Régimen, Logroño. B.A.R.,133 pp.

SÁENZ TERREROS, M.V. 1986

"Historia textil de Ezcaray": Segundo Coloquio sobre Historia de La Rioja vol. II, 229-242, Logroño. 
SAÍNZ RIPA, E. 1979

Archivo de Santa María de La Redonda. Catálogo Documental siglos XVI y XVII, Logroño. $520 \mathrm{pp}$.

SÁINZ RIPA, E. 1986

"Reacción e los eclesiásticos logroñeses ante el impuesto de la sisa en los siglos XVI y XVII": Segundo Coloquio sobre Historia de La Rioja vol. II, 101-110, Logroño.

SÁINZ RIPA, E. 1992

Santa María de La Redonda, de iglesia parroquial a iglesia concatedral, siglos XII al XX. Logroño. Col. Logroño.

SOBRÓN ELGUEA, M.C. 1986

Logroño en la Guerra de la Independencia, Logroño. B.A.R., 354 pp.

SOPEÑA, G. 1994

El florido pensil, Madrid.

THOMPSON, I.A.A., 1981

"El Concejo abierto de Alfaro en 1602: la lucha por la democracia municipal en la Castilla seiscientista": Berceo 100, 307-331.

TORREALBA DOMÍNGUEZ, G. 1989

Política e infraestructura interna del comercio logroñés, 1650-1750, tesis de licenciatura inédita, Universidad de Zaragoza. Un adelanto sobre su tesis, "El pósito de Calahorra en los siglos XVII y XVIII", depositado para su publicación en Brocar.

TORREALBA DOMÍNGUEZ, G. 1992

"Comercio del vino en Logroño: los problemas de la infraestructura comercial y la política oligárquica, 1650-1750": Berceo 122, 79-106.

VALLS MONTÉS. 1984

La interpretación de la Historia de España y sus orígenes ideológicos en el bachillerato franquista, 1938-1953. Universidad de Valencia.

VV.AA. 1973

Miscelánea de Arqueología Riojana, Logroño. 200 pp.

ZULOAGA RADA, M. 1986

"Emigrantes riojanos a América: aproximación a sus estructuras sociales y mentales": Segundo Coloquio sobre Historia de La Rioja vol. II, 91-100, Logroño. 